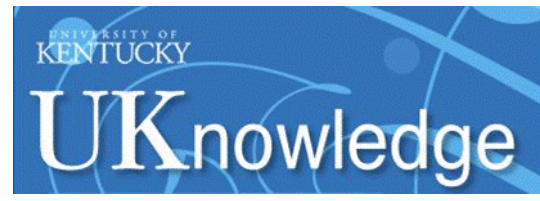

University of Kentucky

UKnowledge

\title{
Rule Conflation in an Inferential-Realizational Theory of Morphotactics
}

Gregory Stump

University of Kentucky, gregory.stump@uky.edu

Follow this and additional works at: https://uknowledge.uky.edu/english_facpub

Part of the English Language and Literature Commons

Right click to open a feedback form in a new tab to let us know how this document benefits you.

\section{Repository Citation}

Stump, Gregory, "Rule Conflation in an Inferential-Realizational Theory of Morphotactics" (2017). English Faculty Publications. 6.

https://uknowledge.uky.edu/english_facpub/6

This Article is brought to you for free and open access by the English at UKnowledge. It has been accepted for inclusion in English Faculty Publications by an authorized administrator of UKnowledge. For more information, please contact UKnowledge@lsv.uky.edu. 


\section{Rule Conflation in an Inferential-Realizational Theory of Morphotactics}

Digital Object Identifier (DOI)

https://doi.org/10.1556/2062.2017.64.1.3

\section{Notes/Citation Information}

Published in Acta Linguistica Academica, v. 64, issue 1, p. 79-124.

๑ 2017 Akadémiai Kiadó, Budapest

The copyright holder has granted the permission for posting the article here. 


\title{
Rule conflation in an inferential-realizational theory of morphotactics
}

\author{
Gregory Stump \\ University of Kentucky \\ gstump@uky.edu
}

\begin{abstract}
In intuitive terms to be sharpened below, the micromorphology hypothesis is the hypothesis that an affix can itself be morphologically complex. This is a widespread assumption in descriptive accounts of the morphology of individual languages; yet, with only the rarest exceptions (e.g., the proposals of Bauer 1988; Bochner 1992 and Luís \& Spencer 2005), morphological theory has tended to reject this hypothesis, most often tacitly. My objective here is therefore threefold. I begin by characterizing the micromorphology hypothesis in more precise terms, exemplifying it with the analysis of nominal inflection in Noon (Niger Congo/Atlantic; Senegal) presented by Soukka (2000) and showing that in a rule-based conception of morphology, this hypothesis entails an operation of rule conflation similar (though not identical) to the operation of function composition in mathematics. I propose an inferential realizational morphological theory that implements the micromorphology hypothesis by incorporating the notion of rule conflation. I demonstrate its basic properties with regard to the Noon evidence. I survey several kinds of evidence that favor the conciliation of morphological theory with the micromorphology hypothesis and therefore necessitate a rather profound rethinking of the principles of morphotactics. I discuss a number of apparent morphotactic anomalies that can be readily accounted for by assuming that the default patterns of interaction among a language's morphological rules can be overridden by the conflation of two or more rules. I conclude by discussing the wider implications of the micromorphology hypothesis for refining a theory of inflectional exponence, observing that rule conflation is only one of the ways in which current conceptions of the algebra of morphotactics must be improved upon.
\end{abstract}

Keywords: morphotactics; rule conflation; Noon language; micromorphology hypothesis; affixation

\section{The micromorphology hypothesis}

\subsection{An analysis of Noon adjective inflection embodying the micromorphology hypothesis}

In her description of the Noon language, Soukka (2000) presents a detailed account of the Noon noun-class system. In this system, adjectives exhibit a complex pattern of inflection: 
(i) An adjective agrees with its controller noun in definiteness and number: agreement is expressed by means of an "attributive prefix" expressing number and (in definite forms) by a "definite suffix" expressing both number and definiteness (Soukka 2000, 87).

(ii) Definite nouns inflect for the position of their referent (location 1 'near the speaker', location 2 'near the addressee', location 3 'near neither speaker nor addressee'); accordingly, a definite adjective's definite suffix also expresses agreement with its controller noun's position inflection.

(iii) The affixal expression of both number agreement and definite agreement depends on whether the controller noun is diminutive or nondiminutive; if it is nondiminutive, it additionally depends on whether the controller noun is in the animate class or the inanimate class; and if it is inanimate, it additionally depends on the controller noun's membership in one of six noun classes.

This inflectional complexity is exemplified by the paradigm of the adjective $^{1}$ YAK 'big' in Table 1.

Table 1: The inflection of the Noon adjective YAK 'big'

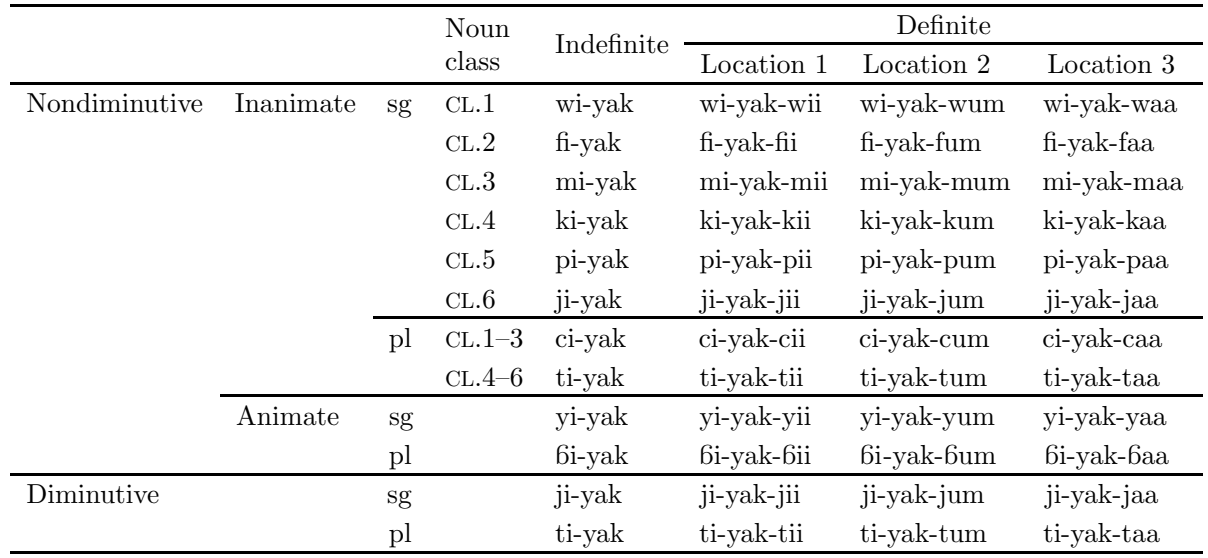

Soukka observes that each of the affixes in Table 1 is morphologically complex: each attributive prefix consists of a class marker and a prefixal

${ }^{1}$ This adjective belongs to a subclass whose members also function as stative verbs (Soukka 2000, 88-89). 
formative $i$-, and each definite suffix consists of a class marker and one of the positional formatives - $-i i,-u m$ and $-a a$. These components of the affixes in Table 1 are distinguished in Table 2 .

Table 2: Components of Noon adjectival inflections

\begin{tabular}{|c|c|c|c|c|}
\hline & & & $\begin{array}{l}\text { Noun } \\
\text { class }\end{array}$ & $\begin{array}{l}\text { Class } \\
\text { marker }\end{array}$ \\
\hline \multirow[t]{10}{*}{ Nondiminutive } & Inanimate & $\mathrm{sg}$ & CL.1 & $\mathrm{W}-$ \\
\hline & & & CL.2 & $\mathrm{f}-$ \\
\hline & & & CL.3 & m- \\
\hline & & & CL. 4 & k- \\
\hline & & & CL. 5 & p- \\
\hline & & & CL. 6 & j- \\
\hline & & $\mathrm{pl}$ & CL.1-3 & $\mathrm{c}-$ \\
\hline & & & CL.4-6 & t- \\
\hline & Animate & $\mathrm{sg}$ & & $y-$ \\
\hline & & $\mathrm{pl}$ & & $6-$ \\
\hline \multirow[t]{2}{*}{ Diminutive } & & $\mathrm{sg}$ & & j- \\
\hline & & $\mathrm{pl}$ & & t- \\
\hline
\end{tabular}

Attributive prefix $=$ class marker + prefixal formative

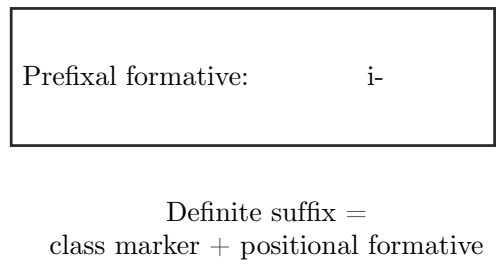

\begin{tabular}{|cc|}
\hline Positional formatives: & \\
Location 1 & $-\mathrm{ii}$ \\
Location 2 & $-\mathrm{um}$ \\
Location 3 & -aa \\
\hline
\end{tabular}

In examining this data, one might suggest that the adjectival forms in Table 1 do not simply exhibit a single prefix and (in the case of the definite forms) a single suffix; instead, one might claim that a form like wiyakwum 'big (nondiminutive inanimate singular class CL.1 definite location 2)' actually has two prefixes and two suffixes, as in Table 3 (overleaf). But this way of looking at the morphology of Noon adjectives complicates things, because it requires us to say that the noun-class affixes function sometimes as prefixes and sometimes as suffixes. This problem doesn't arise in Soukka's analysis, in which the noun-class markers are invariably prefixal: in the formation of attributive prefixes, they are prefixed to the prefixal formative $i$-, and in the formation of definite suffixes, they are prefixed to the positional formatives - $-i i$, $-u m$ and - $a a$. Thus, Soukka's analysis doesn't deny that there are four affixes in wiyakwum; it only denies that these affixes are affixed in a piecemeal, purely linear fashion. Instead, it entails that $w$ - is prefixed to $i$ - to form a complex prefix $w$ - $i$-; that $w$ - is prefixed to -um to form a complex suffix -w-um; and that it is these complex affixes $w-i$ - and -w-um that are affixed to yak to form wiyakwum, as in Table 4.

Soukka's analysis therefore embodies the micromorphology hypothesis - the hypothesis that affixes themselves may be morphologically complex. This is an idea that morphologists have taken up from time to time 
Table 3: The inflection of the Noon adjective YAK 'big'

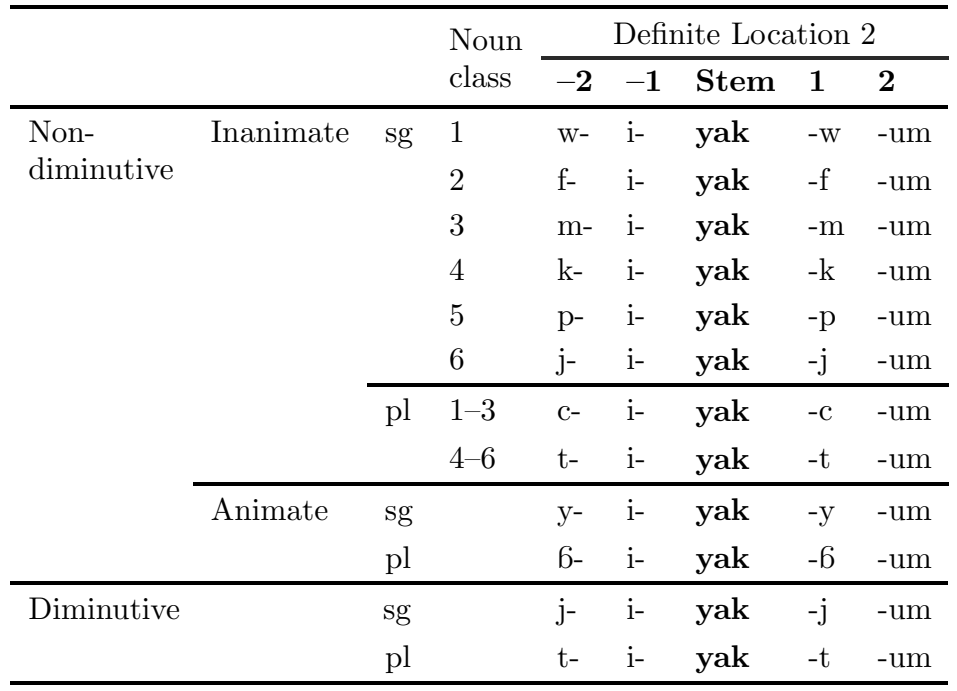

(e.g., Bochner 1992; Luís \& Spencer 2005), but in general, the micromorphology hypothesis has not won much favor among theorists. Yet, as I show below (§3), there are certain morphological phenomena that make it an attractive hypothesis. Before proceeding to these phenomena, it is important to formulate the notion of rule conflation in sharper terms $(\S 1.2)$ and to situate this notion within a precise conception of inflectional morphology $(\S 2)$.

\subsection{The operation of rule conflation}

In its simplest formulation, the micromorphology hypothesis is a hypothesis about affixes, as in (1).

(1) Affix-oriented formulation:

In the most adequate description of a language's morphology, an affix may be morphologically complex, i.e., a combination of other affixes.

The micromorphology hypothesis might, however, be articulated in a slightly different way. Under the assumption that affixes are markings licensed by morphological rules, the micromorphology hypothesis can be formulated as a hypothesis entailing that a rule of affixation may itself be 
Table 4: The inflection of the Noon adjective YAK 'big'

\begin{tabular}{|c|c|c|c|c|c|c|}
\hline & & & $\begin{array}{l}\text { Noun } \\
\text { class }\end{array}$ & $\begin{array}{l}\text { Attributive } \\
\text { prefix }\end{array}$ & Stem & $\begin{array}{c}\text { Definite } \\
\text { suffix } \\
\text { (Location 2) }\end{array}$ \\
\hline \multirow{10}{*}{$\begin{array}{l}\text { Non- } \\
\text { diminutive }\end{array}$} & \multirow[t]{8}{*}{ Inanimate } & \multirow[t]{6}{*}{$\mathrm{sg}$} & 1 & $\mathrm{w}-\mathrm{i}-$ & yak & -w-um \\
\hline & & & 2 & f-i- & yak & -f-um \\
\hline & & & 3 & m-i- & yak & $-m-u m$ \\
\hline & & & 4 & $\mathrm{k}-\mathrm{i}-$ & yak & -k-um \\
\hline & & & 5 & p-i- & yak & -p-um \\
\hline & & & 6 & $\mathrm{j}-\mathrm{i}-$ & yak & -j-um \\
\hline & & \multirow[t]{2}{*}{$\mathrm{pl}$} & $1-3$ & c-i- & yak & -c-um \\
\hline & & & $4-6$ & $\mathrm{t}-\mathrm{i}-$ & yak & -t-um \\
\hline & \multirow[t]{2}{*}{ Animate } & $\mathrm{sg}$ & & $y-i-$ & yak & $-y-u m$ \\
\hline & & $\mathrm{pl}$ & & 6-i- & yak & $-6-u m$ \\
\hline \multirow[t]{2}{*}{ Diminutive } & & $\mathrm{sg}$ & & $\mathrm{j}-\mathrm{i}-$ & yak & $-j-u m$ \\
\hline & & $\mathrm{pl}$ & & t-i- & yak & -t-um \\
\hline
\end{tabular}

the complex conflation of more basic rules of affixation. ${ }^{2}$ Thus, the micromorphology hypothesis has the more general, rule-oriented conception in (2).

(2) Rule-oriented formulation:

In the most adequate description of a language's morphology, a rule of affixation may be morphologically complex, i.e., the conflation of other rules of affixation.

The notion of rule conflation at issue here is in some ways similar to that of function composition in mathematics, where the function $(g \circ f)$ is the composition of the functions $g$ and $f$ if and only if for any $x$ in the domain of $f,(g \circ f)(x)=g(f(x))$. Thus, just as the composition of the function $g$ in (3b) with the function $f$ in (3a) produces the function $(g \circ f)$ in $(3 \mathrm{c})$, so the conflation of the derivational rule (4b) with the derivational rule (4a) produces the conflated derivational rule (4c).

${ }^{2}$ A priori, there is no reason why the morphological rules that enter into such conflations must necessarily be affixational. The most convincing cases, however, do involve affixation, and I shall focus exclusively on such cases here. Nevertheless, nothing that I say here should be seen as excluding the possibility that nonconcatenative rules might also enter into relations of rule conflation. 
(3) Function composition
a. $f(n)=n \times 2$
$(2 \rightarrow 4)$
b. $g(n)=n+1$
$(4 \rightarrow 5)$
c. $(g \circ f)(n)=(n \times 2)+1$
$(2 \rightarrow 5)$

(4) Rule conflation
a. $\quad \mathrm{X}-$ ate $=\mathrm{V}$
(hyphen, valid $\rightarrow$ hyphenate, validate)
b. $\mathrm{V}-$ ion $=\mathrm{N}$
(hyphenate, validate $\rightarrow$ hyphenation, validation)
c. $\quad \mathrm{X}-$ at-ion $=\mathrm{N}$
(hyphen, valid $\rightarrow$ hyphenation, validation)

The analogy of rule conflation to function composition works in (4) because the rules involved are all rules of suffixation. But the conflation of a rule of prefixation with a rule of suffixation (or of a rule of suffixation with a rule of prefixation) does not submit to the same analogy. In general, I define rule conflation as in (5).

(5) Where $\mathrm{A}$ is a rule that affixes $a$ and $\mathrm{B}$ is a rule that affixes $b$, the conflation of $\mathbf{A}$ with $\mathbf{B}$ is a rule $\left[\mathrm{A}(\mathrm{C}) \mathrm{B}\right.$ ] that affixes $b^{\prime}$, where (i) $b^{\prime}$ is the result of applying $\mathrm{A}$ to $b$ and (ii) $[\mathrm{A}(\mathrm{C}) \mathrm{B}]$ effects the same operation (prefixation or suffixation) as B. ${ }^{3}$

According to this definition, there are four logically possible patterns of rule conflation; these are represented schematically in Table 5 . The conflation of A with B is analogous to function composition when A and B both effect prefixation or when both effect suffixation. But when A is prefixational and $\mathrm{B}$ is suffixational, the application of [A (C) B] to stem $\mathrm{X}$ is $\mathrm{X} a b$ rather than $a \mathrm{X} b$; and when $\mathrm{A}$ is suffixational and $\mathrm{B}$ is prefixational, the application of [A (C) B] to stem $\mathrm{X}$ is $b a \mathrm{X}$ rather than $b \mathrm{X} a$. In these latter cases, the conflation of A with $\mathrm{B}$ cannot be equated with the mathematical notion of function composition.

${ }^{3}$ A colleague suggested that the rule conflation is incompatible with the amorphousness hypothesis (i), a central assumption in earlier work in Paradigm Function Morphology.

(i) The amorphousness hypothesis

An uncompounded word's morphological form is not distinct from its phonological form.

(Cf. Janda 1983; Anderson 1992; Stump 2001.)

There is no incompatibility, however. Because of the way rule conflation is defined, the forms defined by a conflated rule, like those defined by a simple rule, are phonological forms: they have neither a branching morphological constituent structure nor a morphological bracketing, nor are they sets or sequences of discrete Bloomfieldian morphemes separated by commas. They are phonological representations pure and simple. 
Table 5: Four logically possible patterns of rule conflation

\begin{tabular}{cccc}
\hline Rule A & Rule B & Rule [A C B] & $\begin{array}{c}\text { The application } \\
\text { of [A C B] to stem X }\end{array}$ \\
\hline$a$-prefixation & $b$-prefixation & $a b$-prefixation & $a b \mathrm{X}$ \\
$a$-prefixation & $b$-suffixation & $a b$-suffixation & $\mathrm{X} a b$ \\
$a$-suffixation & $b$-prefixation & $b a$-prefixation & $b a \mathrm{X}$ \\
$a$-suffixation & $b$-suffixation & $b a$-suffixation & $\mathrm{X} b a$ \\
\hline
\end{tabular}

Four characteristics of the general definition of rule conflation in (5) should be carefully noted:

- Rule B has a dominant role in the interpretation of the conflated rule $[\mathrm{A}(\mathrm{C}) \mathrm{B}]$, since the direction of affixation of $\mathrm{B}$ determines that of $[\mathrm{A}(\mathrm{C}) \mathrm{B}]$, as in Table 5 .

- In the application of [A (C) B] to a stem X, A's affix is always sequenced primarily with respect to B's affix, which alone determines the sequence of affixation with respect to $\mathrm{X}$.

- The definition of rule conflation does not exclude the possibility that a conflated rule might itself enter into the conflation of a still more complex rule; that is, rule conflation may be recursive.

- Rule conflation is an operation on rules rather than on affixes; nevertheless, if $\mathrm{A}$ and $\mathrm{B}$ are rules introducing the respective affixes $a$ and $b$, I will, as a kind of shorthand, refer to the affix $a b$ (or $b a$ ) introduced by the conflated rule [A (C) B] as a conflated affix.

The definition in (5) determines the formal effects of rule conflation, and applies to both inflectional and derivational rules. But what about the content expressed by a conflated rule? This content naturally depends on whether the rules involved are rules of inflectional realization or rules of derivation. Consider first the case of realizational rules of inflectional affixation; here and below, I use the notation

$$
\{\sigma\} \text { : affix } x
$$

to represent an inflectional rule realizing the morphosyntactic property set $\{\sigma\}$ through the affixation of $x$. If rule A realizes the morphosyntactic property set $\{\alpha\}$ and rule $B$ realizes the property set $\{\beta\}$, then rule 
[A (C) B] realizes the combination of these property sets. In the simplest cases, the relevant mode of combination can simply be seen as set union: $\{\alpha\} \cup\{\beta\}$. But in the general case, it is preferable to regard the mode of set combination as unification ${ }^{4}$ for instance, the combination of $\{$ TNS:fut, AGR: $\{3 \mathrm{sg}\}\}$ with $\{$ AGR: $\{$ fem $\}\}$ should be the unification $\{$ TNS:fut, AGR: $\{3$ sg fem $\}\}$ rather than the union \{Tns:fut, AGR: $\{3 \mathrm{sg}\}$, AGR: $\{\mathrm{fem}\}\}$. Accordingly, if $\mathrm{A}$ and $\mathrm{B}$ are inflectional rules such that $\mathrm{A}$ realizes $\{\alpha\}$ and $B$ realizes $\{\beta\}$, then $[A(C)$ ] realizes the unification $\{\alpha\} \sqcup\{\beta\}$. Thus, in the inflectional domain, the content expressed by rule conflation may be schematized as in Table 6.

Table 6: The content expressed by rule conflation in the inflectional domain

\begin{aligned} & \hline Rule A. $\{\alpha\}:$ prefix $a- \\ &$ Rule B. $\{\beta\}:$ suffix $-b \\ &$\hline Rule [A C B]. $\{\alpha\} \sqcup\{\beta\}:$ suffix $-a-b \\ &$\hline\end{aligned}

Where rules of derivational affixation are involved, the situation is somewhat more complex; here and below, I use the notation

$$
\text { affix } y\left|\mathrm{C}_{1} \rightarrow \mathrm{C}_{2}\right| \llbracket L \rrbracket \rightarrow f(\llbracket L \rrbracket)
$$

to represent a rule of derivation that applies to a lexeme $L$ of category $\mathrm{C}_{1}$ with meaning $\llbracket L \rrbracket$ and stem $\mathrm{X}$ to produce a lexeme $L^{\prime}$ of category $\mathrm{C}_{2}$ with meaning $f(\llbracket L \rrbracket)$ and stem $\mathrm{X}^{\prime}$, the result of affixing $y$ to $\mathrm{X}$. Suppose now that

${ }^{4}$ The assumed definition of unification is as in (i); this definition depends on the assumed definition of extension in (ii).

(i) The unification of $\rho$ and $\sigma$ (i.e., $\rho \sqcup \sigma$ ) is the smallest well-formed extension of both $\rho$ and $\sigma$.

Example: $\{$ SBJ: $\{$ PER:3, NUM:sg $\}$, OBJ: $\{$ NUM:pl $\}\} \sqcup\{$ TNS:prs, OBJ:\{PER: 1$\}\}$ $=\{\mathrm{SBJ}:\{$ PER:3, NUM:sg $\}$, TNS:prs, OBJ:\{PER:1, NUM:pl $\}\}$

(ii) Given two sets $\sigma, \tau: \sigma$ is an extension of $\tau$ (i.e., $\tau \sqsubseteq \sigma$ ) iff for each property F:x $\in \tau$, either (i) $\mathrm{F}$ is an atom-valued feature and $\mathrm{F}: \mathrm{x} \in \sigma$

or (ii) $\mathrm{F}$ is a set-valued feature such that $\mathrm{F}: \mathrm{y} \in \sigma$ and $\mathrm{y}$ is an extension of $\mathrm{x}$. Examples: $\quad$ NNUM:pl $\} \sqsubseteq\{$ PER:1, NUM:pl $\}$ \{TNS:prs, OBJ:\{PER:1 $\}\} \sqsubseteq\{$ TNS:prs, OBJ:\{PER:1, NUM:pl $\}\}$ 
(i) a derivational rule $\mathrm{D}$ applies to a lexeme $L$ of category $\mathrm{C}_{1}$ with meaning $\llbracket L \rrbracket$ and stem $\mathrm{X}$ to produce a lexeme $L^{\prime}$ of category $\mathrm{C}_{2}$ with meaning $f(\llbracket L \rrbracket)$ and stem $\mathrm{X}^{\prime}$, the result of prefixing $a$ - to $\mathrm{X}$; and

(ii) a derivational rule $\mathrm{E}$ applies to a lexeme $L$ of category $\mathrm{C}_{2}$ with meaning $\llbracket L \rrbracket$ and stem $\mathrm{X}$ to produce a lexeme $L^{\prime}$ of category $\mathrm{C}_{3}$ with meaning $g(\llbracket L \rrbracket)$ and stem $\mathrm{X}^{\prime}$, the result of suffixing $-b$ to $\mathrm{X}$.

In that case, the conflated rule [E (C) D] applies to a lexeme L of category $\mathrm{C}_{1}$ with meaning $\llbracket L \rrbracket$ and stem $\mathrm{X}$ to produce a lexeme $L^{\prime}$ of category $\mathrm{C}_{3}$ with meaning $g(f(\llbracket L \rrbracket))$ and stem $\mathrm{X}^{\prime}$, the result of prefixing $a$-b- to $\mathrm{X}$. The content expressed by rule conflation in the derivational domain may therefore be schematized as in Table 7 .

Table 7: The content expressed by rule conflation in the derivational domain

\begin{aligned} & \hline Rule D. prefix $a$ - $\left|\mathrm{C}_{1} \rightarrow \mathrm{C}_{2}\right| \llbracket L \rrbracket \rightarrow f(\llbracket L \rrbracket) \\ &$ Rule E. suffix $-b\left|\mathrm{C}_{2} \rightarrow \mathrm{C}_{3}\right| \llbracket L \rrbracket \rightarrow g(\llbracket L \rrbracket) \\ &$ Rule [E C D]. prefix $a b-\left|\mathrm{C}_{1} \rightarrow \mathrm{C}_{3}\right| \llbracket L \rrbracket \rightarrow g(f(\llbracket L \rrbracket)) \\ &$\hline\end{aligned}

This conception of rule conflation affords a straightforward representation of Soukka's analysis of Noon adjective agreement. In the following section, I develop this representation of her analysis in formal detail.

\section{A formal theory of rule conflation in inflectional morphology}

The notion of rule conflation developed here can be straightforwardly integrated into an inferential-realizational theory of inflection whose fundamental characteristics are those of Paradigm Function Morphology $(\mathrm{PFM}) .{ }^{5}$ Some key assumptions underlying this theory are (i)-(v):

(i) A lexeme's inflectional paradigm is a set of cells, each the pairing of a stem with a morphosyntactic property set. For any cell $\langle X, \sigma\rangle$ in the paradigm of lexeme $L, \sigma$ must be a property set with which

${ }^{5}$ Some of the principal references relating to PFM are Stump $(1991 ; 1993 ; 2001 ; 2012$; 2016); Stewart \& Stump (2007); Spencer \& Stump (2013); and Bonami \& Stump (2017). 
$L$ may be associated in syntax and $X$ must be that member of $L$ 's stem inventory that is appropriate for the realization of $\sigma .^{6}$

(ii) Each language has a paradigm function which applies to each cell $\langle X, \sigma\rangle$ in the paradigm of a given lexeme $L$ to produce the corresponding realized cell $\left\langle X^{\prime}, \sigma\right\rangle$ such that $X^{\prime}$ is the word form realizing $L$ and $\sigma$. The definition of a language's inflectional morphology is that of its paradigm function.

(iii) A language's paradigm function is defined by means of individual rules that apply to the pairing $\langle X, \sigma\rangle$ of a stem $X$ with a morphosyntactic property set $\sigma$ to produce a new pairing $\left\langle X^{\prime}, \sigma\right\rangle$ such that $X^{\prime}$ realizes one or more of the properties in $\sigma .{ }^{7}$

(iv) These realizational rules are organized into blocks whose members are in paradigmatic opposition (mutually exclusive in their application). If two members of the same block are both applicable to the pairing $\langle X, \sigma\rangle$, this competition is resolved in favor of the narrower rule by Pānini's principle (Stump 2001, 22). Where $\langle X, \sigma\rangle$ is the pairing of a stem $X$ with a morphosyntactic property set $\sigma$ and $\boldsymbol{b}$ is a rule block, the notation $[\boldsymbol{b}:\langle X, \sigma\rangle]$ represents the result of applying the narrowest applicable rule in $\boldsymbol{b}$ to $\langle X, \sigma\rangle$.

(v) The order of application of individual realizational rules is determined by the ordering of the blocks to which they belong, which is itself specified in the definition of the language's paradigm function.

I now additionally assume that rules of inflectional affixation may be formulated in two ways: rules that associate morphologically unanalyzable

${ }^{6}$ Stump (2016) argues that the morphosyntactic property set determining a word form's syntax and semantics may be distinct from the property set determining its inflectional realization, and that this fact motivates a theory of inflectional morphology in which a lexeme $L$ 's content paradigm (from which the syntax and semantics of $L$ 's word forms are projected) is distinct from its stem's form paradigm (from which $L$ 's inflectional realizations are projected). In this sort of theory, the morphotactic facts at issue here should be seen as pertaining to the realization of form paradigms.

${ }^{7}$ Stump (to appear b) argues that a rule of affixation should itself be conceived of as two independent rules, one defining the affix as an exponent of a particular set of morphosyntactic properties, the other specifying the manner of its combination with a stem. (This recalls the proposed syntactic distinction between rules of immediate dominance and rules of linear precedence; Gazdar et al. 1985.) Though I do not insist on this distinction here, it is in no way incompatible with the micromorphology hypothesis. 
affixes with particular property sets are simply stipulated as members of one or another rule block, while morphologically complex affixes are associated with property sets by rule conflation. I further assume that in the inflectional domain, the dominance of rule B in the interpretation of a conflated rule [A (C) B] is manifested in two ways: besides sharing B's direction of affixation, [A C B] also shares B's rule-block membership. (Rule A, by contrast, may or may not belong to this same block.)

Consider, now, how this inferential-realizational theory of inflection incorporating rule conflation may be applied in the analysis of Noon adjective inflection. This analysis is based on the simple rules of inflectional affixation in (6): these include rules $(6 \mathrm{a}-1)$ for noun-class prefixes, including the markers of diminutivity and animacy; rule $(6 \mathrm{~m})$ for the prefixal formative $i$-; and rules $(6 \mathrm{n}-\mathrm{p})$ for the positional formatives $-i i,-u m$ and $-a a$.

(6) Simple rules of inflectional affixation for Noon adjective inflection

\section{Block I}

Noun-class rules

a. $\quad\{-\operatorname{dim}-\operatorname{anim} \operatorname{sg}$ CL. 1$\}$ : prefix $w$ -

b. $\quad\{-\operatorname{dim}-\operatorname{anim}$ sg CL. 2$\}$ : prefix $f$ -

c. $\quad\{-\operatorname{dim}-\operatorname{anim}$ sg CL. 3$\}$ : prefix $m$ -

d. $\{-\operatorname{dim}-\operatorname{anim}$ sg CL. 4$\}$ : prefix $k$ -

e. $\{-\operatorname{dim}-\operatorname{anim} \operatorname{sg}$ CL. 5$\}$ : prefix $p$ -

f. $\quad\{-\operatorname{dim}-\operatorname{anim}$ sg CL. 6$\}:$ prefix $j-$

g. $\{-\operatorname{dim}-\operatorname{anim}$ pl CL.1-3\} : prefix $c$ -

h. $\quad\{-\operatorname{dim}-\operatorname{anim}$ pl CL.4-6\} : prefix $t$ -

i. $\quad\{-\operatorname{dim}+\operatorname{anim} \mathrm{sg}\}$ : prefix $y$ -

j. $\{-\operatorname{dim}+$ anim pl $\}$ prefix 6 -

k. $\{+\operatorname{dim} \mathrm{sg}\}:$ prefix $j$ -

1. $\{+\operatorname{dim} \mathrm{pl}\}$ : prefix $t$ -

Prefixal formative rule

m. $\{\operatorname{adj}\}:$ prefix $i_{-}^{8}$

\section{Block II}

Positional formative rules

n. $\{$ definite loc1\} : suffix -ii

o. $\{$ definite loc 2$\}$ : suffix - um

p. $\{$ definite loc 3$\}$ : suffix $-a a$

${ }^{8}$ Rule $(6 \mathrm{~m})$ is formulated as realizing the property 'adjective' because Noon attributive prefixes only participate in the inflection of adjectives. This property is not realized by the definite suffixes, since these participate in the inflection of nouns as well as adjectives. 
By the rule conflation schema in (7a), the noun-class rules in (6a-1) conflate with the prefixal formative rule $(6 \mathrm{~m})$ to produce attributive prefix rules belonging to Block I; by schema (7b), the noun-class rules conflate with the positional formative rules in $(6 n-p)$ to produce the definite suffix rules belonging to Block II.

(7) Conflated rules of inflectional affixation

a. Attributive prefix rules

Given any noun-class rule A, [A (C) (6m)] is an attributive prefix rule $(\in$ Block I) Example: [(6a) C (6m)]

$=\{-\operatorname{dim}$-anim sg CL. 1 adj $\}$ : prefix wi-

is an attributive prefix rule $(\in$ Block $\mathbf{I})$.

b. Definite suffix rules

Given any noun-class rule A and any positional formative rule B, $[\mathrm{A}(\mathrm{C}) \mathrm{B}]$ is a definite suffix rule $(\in$ Block II).

Example: [(6a) C) (6o)]

$=\{$-dim -anim sg CL.1 definite loc2 $\}$ : suffix -wum

is a definite suffix rule $(\in$ Block $\mathbf{I I})$.

The paradigm function defined in (8) guarantees the participation of both of the sorts of rule blocks in (6) in the definition of an adjective's inflected forms. ${ }^{9}$

(8) Paradigm function

$\mathrm{PF}(\langle X, \sigma\rangle)=[$ Block II : [Block I : $\langle X, \sigma\rangle]]$

Example: Where $\sigma=\{-\operatorname{dim}$-anim sg CL.1 definite loc2 adj $\}$,

$\mathrm{PF}(\langle y a k, \sigma\rangle)=[$ Block II : [Block I : $\langle X, \sigma\rangle]]=\langle$ wiyakwum, $\sigma\rangle$

In this analysis, the conflation of noun-class rules with the prefixal formative rule $(6 \mathrm{~m})$ causes noun-class markers to appear before an adjective's stem, as part of its attributive prefix. But the conflation of noun-class rules with the positional formative rules causes noun-class markers to appear after an adjective's stem, as part of its definite suffix. Both of these uses of the noun-class markers are exemplified in the inflection of wiyakwum 'big' (nondiminutive inanimate definite singular class CL.1 location 2).

Figure 1 provides a complete analysis of wiyakwum in the system described here. As Figure 1 shows, wiyakwum involves the stem yak 'big', the noun-class rule (6a), the prefixal formative rule $(6 \mathrm{~m})$, and the positional

${ }^{9}$ There is no rule in Block II that is applicable in the realization of an indefinite paradigm cell such as

$\langle y a k,\{-\operatorname{dim}$-anim -definite sg CL.1 adj $\}\rangle$.

In such cases, the Identity Function Default (Stump 2001, 53) entails that [Block II : $\langle X, \sigma\rangle]=\langle X, \sigma\rangle$. 
formative rule (6o). In accordance with (7a), the noun-class rule conflates with the prefixal formative rule to produce the attributive prefix rule

$$
\{-\operatorname{dim}-\text { anim sg CL.1 adj\} : prefix wi-; }
$$

by $(7 \mathrm{~b})$, the noun-class rule also conflates with the positional formative rule to produce the definite suffix rule

$$
\text { \{-dim -anim sg CL.1 definite loc2\}: suffix -wum. }
$$

The paradigm function (8) causes the attributive prefix rule to apply in Block I and the definite suffix rule to apply in Block II. In this way, the paradigm cell

$$
\langle y a k,\{-\operatorname{dim} \text {-anim sg CL.1 definite loc2 adj\}〉 }
$$

is realized as

$$
\langle\text { wiyakwum, }\{-\operatorname{dim} \text {-anim sg CL.1 definite loc2 adj }\}\rangle \text {. }
$$

\begin{tabular}{|l|ccc|}
\hline $\begin{array}{l}\text { Rules of } \\
\text { inflectional } \\
\text { affixation }\end{array}$ & simple & $(\underbrace{6 \mathrm{a}),(6 \mathrm{~m})}$ & $\underbrace{(6 \mathrm{a}),(6 \mathrm{o})}$ \\
Properties realized & -dim - anim sg CL.1 adj & -dim - anim sg CL.1 definite loc2 \\
Rule block & Block I & Block II \\
Stem: $y a k$ & $\rightarrow$ wiyak & $\rightarrow$ wiyakwum \\
\hline
\end{tabular}

Figure 1: The realization of Noon wiyakwum 'big'

In this analysis, the noun-class affixes are not seen as prefixal in one use and suffixal in another; rather, they are uniformly prefixal, being prefixed to the prefixal formative $i$ - in one use and to the suffixal positional formatives $-i i$, - um and $-a a$ in another use.

Unlike most familiar theories of morphology, the micromorphological theory proposed here is not stem-centric. In many theories, an affix may only join with a stem; theories that conform to this requirement exhibit linear stem-centricity, as in the representation in Figure 2. The informationbased theory of morphology developed by Crysmann and Bonami (2016) is not linearly stem-centric, but is stem-centric in a different way: in this theory, a word form is represented as a sequence of morphs $\left\langle m_{1}, \ldots, m_{n}\right\rangle-$ that 
is, as a flat representation in which all affixes have the same hierarchical rank as the word's stem. Theories requiring this sort of flat structure exhibit hierarchical stem-centricity, as in the representation in Figure 3. The micromorphology hypothesis entails analyses that are stem-centric in neither sense, since the definition of a conflated affix in terms of smaller affixes need not directly involve a stem at all, as in the definition schematized in Figure 4. A natural question is whether the micromorphology hypothesis obliterates the distinction between stems and affixes. Of course it does not: a stem expresses a lexeme, while an affix either realizes a word form's morphosyntactic properties ${ }^{10}$ or serves to derive one lexeme from another.

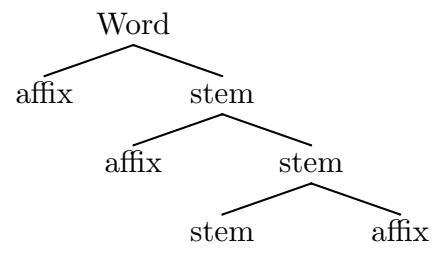

Figure 2: Linear stem centricity (every affix joins with a stem)

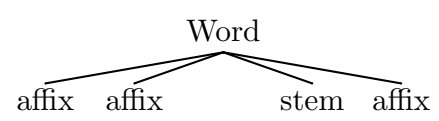

Figure 3: Hierarchical stem-centricity (all affixes have the same hierarchical rank as the stem)

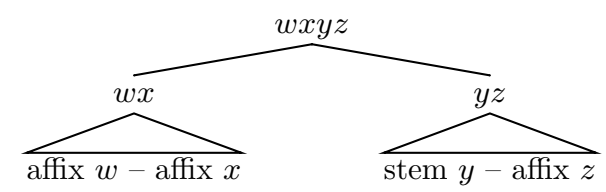

Figure 4: Absence of either sort of stem-centricity in micromorphological definitions $^{11}$

The coherence of the concept of rule conflation exemplified in (6) is not itself at issue. The issue is instead whether the definition of a language's

10 The realization of morphosyntactic properties by an inflectional affix may, of course, be indirect, if that realization involves the mediation of one or more morphomic properties; see Stump 2016, Chapter 8. 
morphology must ever make reference to conflated rules. If so, then that fact is a validation of the micromorphology hypothesis; if not, then the notion of rule conflation is a theoretical redundancy, at most a descriptive convenience. As I now show, there are eleven kinds of evidence that the definition of a language's morphology does involve reference to conflated rules.

\section{Some explanations and interpretations afforded by the micromorphology hypothesis}

The micromorphology hypothesis makes it possible to explain several otherwise puzzling phenomena and additionally affords new interpretations of various phenomena. The phenomena at issue include

- apparently anomalous sequences of rule application (§3.1);

- apparent instances of nonmonotonicity in morphology (§3.2); and

- parallelisms between the application of single rules and that of sequences of rules $(\S 3.3)$.

\subsection{Anomalies in the sequence of rule applications}

What is an anomaly in the sequence of rule applications? In canonical instances of inflectional morphology, each realization rule applies in a particular position in the sequence of rule applications defining a word form's morphology. This canonical situation is cleanly representable by means of a system of linearly ordered blocks of realization rules in which the members of each block are disjunctive in their application (a theoretical architecture argued for extensively and convincingly by Stephen Anderson, e.g., Anderson 1977; 1986; 1992); thus, the suffixation rules involved in the definition of Latin laudābantur 'they were being praised' may be seen as occupying three linearly ordered blocks, as in Table 8. An anomaly in the sequence of rule applications is any kind of deviation from this canonical pattern. Such deviations are of various types.

${ }^{11}$ I emphasize that the representation in Figure 4 is not intended as a hierarchical representation of a word form's structure. Instead, it is a representation of the logical sequence in which the parts of the purely phonological representation wxyz are combined by rules of inflectional realization. 
Table 8: Sequence of rule applications in the definition of Latin laudābantur "they were being praised', realizing the property set $\{3$ pl imperf ind pass $\}$

\begin{tabular}{cccc}
\hline laud $\bar{a}-$ & $-b a$ & $-n t$ & $-u r$ \\
& $\uparrow$ & $\uparrow$ & $\uparrow$ \\
rule realizing & rule realizing & rule realizing \\
\{imperf ind $\}$ & $\{3$ pl $\}$ & \{pass \\
Block I & Block II & Block III \\
\hline
\end{tabular}

\subsubsection{A rule's order of application apparently depends on whether or not another rule applies}

In this sort of deviation from the canonical pattern of rule application, a rule's position in a sequence of rule applications depends on whether some other rule is part of that sequence.

Fula verb morphology presents an example of this sort of morphotactic conditioning. In the relative past tense of Fula verbs, the pronominal object markers in Table 9 follow subject suffixes in the default case, as in $(9 \mathrm{a}, \mathrm{b})$; but when the first-person singular subject suffix - mi coincides with a singular personal object suffix (the second-person singular object suffix - $m A$ or the third-person singular Class 1 object suffix $-m O)$, the affixes appear in the opposite order, as the examples in (9) show. ${ }^{12}$

(9) a. mball-u-mi-6e-'

help-REL.PST.ACT-1SG.SBJ-3PL.CL.2.OBJ-FG

'I helped them.'

b. mball-u-daa-mO-'

help-REL.PST.ACT-2SG.SBJ-3SG.CL.1.OBJ-FG

'You (sg.) helped him.'

12 The morphophonological segments $A$ and $O$ in the second-person singular object suffix $-m A$ and the third-person singular Class 1 suffix $-m O$ are realized sometimes as short $a$ and $o$, sometimes as long $a a$ and $o o$. These alternations between short and long variants are conditioned both by their prosodic context and by the morphosyntactic properties being realized. See Arnott $(1970,213 \mathrm{ff})$ for full details on the relevant conditioning. Because the analytic issues raised by these alternations are orthogonal to the matter of affix ordering at issue here, I simply represent these alternating affixes morphophonologically, as $-m A$ and $-m O$.

At the end of the object markers in Table 9, -' and ${ }^{\mathrm{h}}$ respectively indicate the presence and absence of final glottality. More widely, the distribution of final glottality is grammatically conditioned; for details, see Arnott (1970, 231ff). Note the presence of final glottality (FG) in (9). 
Table 9: Series 5 subject affixes and object suffixes in Fula (Arnott 1970, 194, 212)

\begin{tabular}{|c|c|c|}
\hline $\begin{array}{l}\text { Person, } \\
\text { number }\end{array}$ & $\begin{array}{c}\text { Subject } \\
\text { affix } \\
\text { (Series 5) }\end{array}$ & $\begin{array}{l}\text { Object } \\
\text { suffix }\end{array}$ \\
\hline $1 \mathrm{sg}$ & $-\mathrm{mi}$ & - yam $^{-h}$ \\
\hline $2 \mathrm{sg}$ & $-\mathrm{aa} \sim-$-daa & $-\mathrm{mA}^{-\mathrm{h}}$ \\
\hline $3 \mathrm{sg}$ & - & -dum-h \\
\hline $1 \mathrm{pl}$ & $\min -$ & $-\min -^{h}$ \\
\hline $2 \mathrm{pl}$ incl & -en $\sim$-den & -'en-h \\
\hline $2 \mathrm{pl} \mathrm{excl}$ & -on- $\sim$-don & -'on-h \\
\hline $3 \mathrm{pl}$ & - & $-6 e-'$ \\
\hline
\end{tabular}

\begin{tabular}{lll}
\hline $\begin{array}{c}\text { 3sg } \\
\text { noun } \\
\text { class }\end{array}$ & $\begin{array}{c}\text { Subject } \\
\text { affix } \\
\text { (Series 5) }\end{array}$ & $\begin{array}{l}\text { Object } \\
\text { suffix }\end{array}$ \\
\hline 1 & 'o- mo- & -mO-' \\
3 & ygel- & -ngel-' \\
4 & kal- & -kal-' \\
5 & ygum- & -ygum-' \\
7 & yga- & -yga-' \\
9 & nde- & -nde-' \\
10 & ndi- & -ndi-' \\
11 & ndu- & -ndu-' \\
12 & yga- & -yga-' \\
13 & yge- & -yge-' \\
14 & ygo- & -ygo-' \\
15 & ygu- & -ygu-' \\
16 & ygal- & -ygal-' \\
17 & ygol- & -ygol-' \\
18 & ka- & -ka-' \\
19 & ki- & -ki-' \\
20 & ko- & -ko-' \\
21 & kol- & -kol-' \\
22 & dam- & -dam-' \\
23 & dum- & -dum-' \\
\hline & &
\end{tabular}

c. mball-u-mA-mi-'

help-REL.PST.ACT-2SG.OBJ-1SG.SBJ-FG

'I helped you (sg.).'

d. mball-u-mO-mi-'

help-REL.PST.ACT-3SG.CL.1.OBJ-1SG.SBJ-FG

'I helped him.'

(Stump 1993, 165)

The micromorphology hypothesis affords the following analysis of this variability in affix order in Fula verb inflection. For simplicity, this analysis focuses on a representative fragment of Fula's highly elaborate system:

- It defines the morphology of transitive verbs that exhibit person/ number inflection for both their subject and their object.

- The subject and object markers include first- and second-person markers as well as third-person markers for noun classes 1 and 2; 
as far as the workings of the analysis are concerned, the behavior of the Class 1 and Class 2 markers is representative of that of all of the remaining twenty-three noun classes.

- The proposed analysis does not explicitly provide for all combinations of tense, mood and voice, focusing instead on the relative past active ('rpa'), whose subject affixes are drawn from Series 5 ('Ser5'); but there is no obstacle to extending this analysis to cover all occurring combinations.

- A well-formed property set for a verb in this fragment therefore has an extension

$$
\{\mathrm{SBJ}: \alpha, \text { OBJ: } \beta, \text { rpa, Ser5\}, }
$$

where $\alpha, \beta \in\{\{1 \mathrm{sg}\},\{2 \mathrm{sg}\},\{3 \mathrm{sg}$ CL. 1$\},\{1 \mathrm{pl}\},\{2 \mathrm{pl}$ incl $\}$, $\{2 \mathrm{pl} \mathrm{excl}\},\{3 \mathrm{pl} \mathrm{CL} .2\}\} .{ }^{13}$ Note that the property Ser5 is morphomic (Aronoff 1994) - that is, the fact that rules of subject-agreement affixation fall into five discrete series has no significance outside of the workings of Fula morphology.

The simple rules of inflectional affixation for this fragment are listed in (10); these include rules for subject markers (Series 5), for the tense affix of the relative past active, and for object markers. The application of the two blocks of rules in (10) is determined by the definition of the Fula paradigm function in (11).

${ }^{13}$ I follow Arnott $(1970,134)$ in situating the inclusive/exclusive distinction in the second rather than the first-person of the plural, so that 'inclusive' means 'you and I'. This makes it possible to subsume inclusive forms under certain grammatical generalizations otherwise pertaining to second-person plural forms. 
(10) Simple rules of inflectional affixation for a fragment of Fula verb morphology

Block I : Tense suffixation

a. $\{$ rpa Ser5 $\}$ : suffix $-U^{14}$

\section{Block II:}

Subject affixation

b. $\{$ SBJ: $\{1 \mathrm{sg}\}$ Ser5 $\}$ : suffix $-m i$

Object suffixation

c. $\{$ SBJ: $\{2 \mathrm{sg}\}$ Ser 5$\}$ : suffix $-d a a$

i. $\quad\{$ OBJ: $\{1 \mathrm{sg}\}\}$ : suffix - yam

d. $\{$ SBJ: $\{3$ sg CL. 1$\}$ Ser5 $\}$ : prefix'o-

j. $\{$ OBJ: $\{2 \mathrm{sg}\}\}$ : suffix $-m A$

e. $\{\mathrm{SBJ}:\{1 \mathrm{pl}\}$ Ser5 $\}$ : prefix min-

k. $\quad\{$ OBJ: $\{3$ sg CL. 1$\}\}$ : suffix $-m O$

f. $\{$ SBJ: $\{2 \mathrm{pl}$ incl $\}$ Ser5 $\}$ : suffix - den

1. $\{$ OBJ: $\{1 \mathrm{pl}\}\}$ : suffix - min

g. $\{$ SBJ: $\{2 \mathrm{pl}$ excl $\}$ Ser5 $\}$ : suffix - don

m. $\{$ OBJ: $\{2 \mathrm{pl}$ incl $\}\}$ : suffix -'en

h. $\{$ SBJ: $\{3 \mathrm{pl} \mathrm{CL} .2\}$ Ser 5$\}$ : prefix $6 e-$

n. $\{$ oBJ: $\{2 \mathrm{pl}$ excl $\}\}$ : suffix -'on

o. $\{$ OBJ: $\{3$ pl CL. 2$\}\}$ : suffix $-6 e$

(11) Paradigm function for a fragment of Fula verb morphology

$\mathrm{PF}(\langle X, \sigma\rangle)=[$ Block II : [Block I: $\langle X, \sigma\rangle]]$

Conflated rules of affixal inflection for Block II in the Fula fragment are schematically defined in (12). This definition guarantees that the subjectagreement rule (10b) conflates with the object-agreement rules $(10 \mathrm{j})$ and $(10 \mathrm{k})$, as in (13), but that otherwise, object-agreement rules instead conflate with subject-agreement rules, as for example in (14). The full system of conflated suffixation rules defined in (12) is represented in Table 10, in which ' $\alpha$ ' represents a rule realizing some property set through the suffixation of $\alpha$.

(12) Conflated rules of inflectional affixation for a fragment of Fula verb morphology

Given the rules A. $\{$ SBJ: $\alpha$ Ser 5$\}$ : suffix $X$

B. $\{$ OBJ: $\beta\}$ : suffix $Y$,

a. [A (C) B] is a conflated rule if $\alpha=\{1 \mathrm{sg}\}$ and $\beta \in\{\{2 \mathrm{sg}\},\{3 \mathrm{sg}$ CL. 1$\}\}$;

b. otherwise, $[\mathrm{B}$ (C) $\mathrm{A}]$ is a conflated rule.

(13) a. [(10b) C (10j)] i.e., \{oBJ:\{2 sg $\}$ SBJ: $\{1 \mathrm{sg}\}$ Ser5 $\}$ : suffix $m A m i$

b. $[(10 \mathrm{~b})(\mathrm{C})(10 \mathrm{k})]$ i.e., $\{$ OBJ:\{3 sg CL. 1$\}$ SBJ: $\{1 \mathrm{sg}\}$ Ser5 $\}$ : suffix $m O m i$

(14) $[(10 \mathrm{o})$ C $(10 \mathrm{~b})]$ i.e., $\{\mathrm{SBJ}:\{1 \mathrm{sg}\}$ obJ:\{3 pl CL.2 $\}$ Ser5 $\}$ : suffix mi6e

14 The $-U$ suffix of the relative past active varies in shape according to lexical and morphotactic conditions: it is realized as $-u$ with one class of verb roots (Arnott's "Type 1" roots), has no phonological realization with "Type 2" roots, and is realized as an optional - $u$ with 'Type 3' roots. See Arnott (1970, 187-188) for details concerning this three-way classification of roots. 
Table 10: Conflation of suffixation rules in a fragment of Fula verb inflection

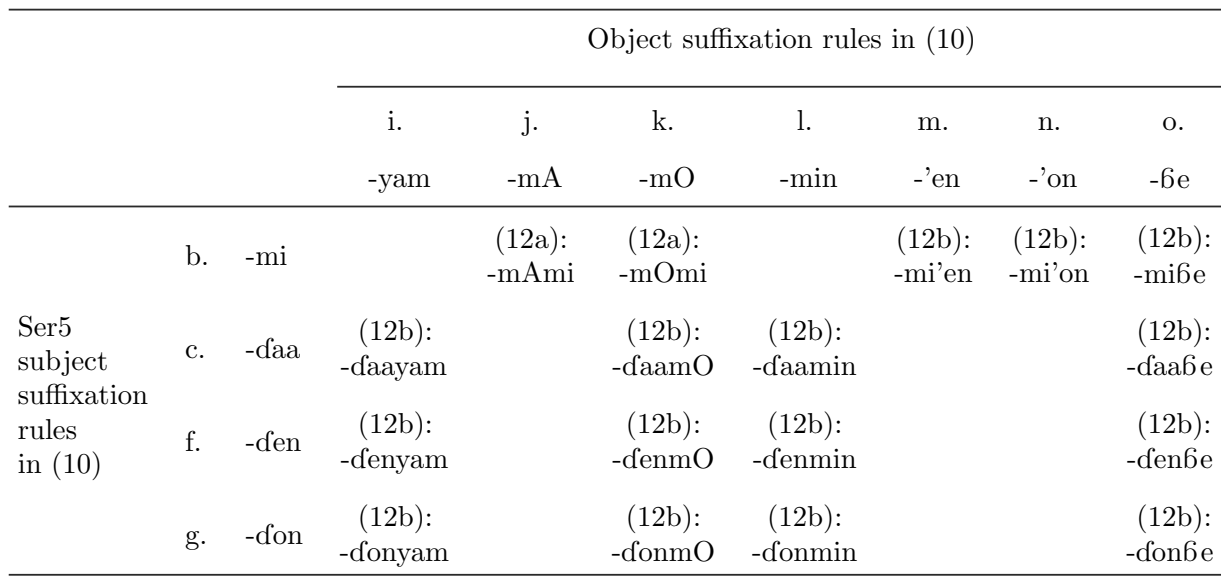

This analysis gives a precise account of the way in which the subjectagreement suffix - $m i$ varies in its ordering. Thus, consider first the realization of mballumife' 'I helped them', which expresses the paradigm cell

$\langle m b a l l,\{$ sBJ: $\{1 \mathrm{sg}\}$ OBJ: $\{3 \mathrm{pl}$ CL. 2$\}$ rpa - pret Ser 5$\}\rangle$.

In this realization, rule (10o) conflates with rule (10b) to produce the conflated rule in (14), which embodies the ordering of subject suffix before object suffix specified by (12b) as the default ordering in relative past active forms. This default is overridden, however, in mballumAmi' 'I helped you (sg.)', the realization of the paradigm cell

$$
\langle\text { mball, }\{\text { SBJ: }\{1 \mathrm{sg}\} \text { OBJ: }\{2 \mathrm{sg}\} \text { rpa }- \text { pret Ser5 }\}\rangle \text {. }
$$

Here, rule $(10 \mathrm{~b})$ conflates with rule $(10 \mathrm{j})$, producing the conflated rule in (13a) in accordance with (12a), and thus overrides the default ordering. These results are schematized in Figures 5 and 6 .

The analysis proposed here for the reversal of subject- and objectagreement marking in Fula differs markedly from the analysis proposed by Stump (1993). That analysis was part of a wider investigation of a range of important challenges for the definition of systems of position-class morphology:

a. parallel position classes: two classes of affixes whose members (i) are virtually the same in form and (ii) express parallel kinds of content but which are associated with distinct affix positions; 


\begin{tabular}{|l|cccc|}
\hline $\begin{array}{l}\text { Rules of } \\
\text { inflectional } \\
\text { affixation }\end{array}$ & simple & $(10 \mathrm{a})$ & $(\underbrace{10 \mathrm{o}),(10 \mathrm{~b})}$ & \\
Properties realized & & {$[(10 \mathrm{o})$ C $(10 \mathrm{~b})]$} & {$[$ by $(12 \mathrm{~b})]$} \\
Rule block & rpa & SBJ: $\{1 \mathrm{sg}\}$ OBJ: $\{3$ pl CL.2 $\}$ Ser5 & \\
Stem: mball & Block I & Block II \\
\hline
\end{tabular}

Figure 5: The realization of Fula mballumibe' 'I helped them' (paradigm cell $\langle m b a l l,\{$ SBJ: $\{1 \mathrm{sg}\}$ OBJ: $\{3$ pl CL. 2$\}$ rpa - pret Ser 5$\}\rangle)$

\begin{tabular}{|c|c|c|c|c|}
\hline $\begin{array}{l}\text { Rules of } \\
\text { inflectional } \\
\text { affixation }\end{array}$ & $\begin{array}{l}\text { simple } \\
\text { conflated }\end{array}$ & $(10 \mathrm{a})$ & $\frac{(\underbrace{10 \mathrm{~b}),(10 \mathrm{j}})}{[(10 \mathrm{~b}) \mathrm{C}(10 \mathrm{j})]}$ & [by (12a)] \\
\hline \multicolumn{2}{|c|}{ Properties realized } & rpa & SBJ: $\{1 \mathrm{sg}\}$ OBJ: $\{2 \mathrm{sg}\}$ Ser5 & \\
\hline \multicolumn{2}{|c|}{ Rule block } & Block I & Block II & \\
\hline \multicolumn{2}{|l|}{ Stem: mball } & $\rightarrow$ mballu & $\rightarrow$ mballumAmi & \\
\hline
\end{tabular}

Figure 6: The realization of Fula mballumAmi' 'I helped you (sg.)' (paradigm cell $\langle$ mball, $\{$ SBJ: $\{1 \mathrm{sg}\}$ OBJ:\{2 sg $\}$ rpa - pret Ser5 $\}\rangle)$

b. portmanteau position classes: classes whose members stand in paradigmatic opposition to sequences of adjacent affixes from other position classes;

c. reversible position classes: classes whose members appear in a default sequence which is reversed when certain members happen to appear together, as in the case of Fula verb agreement; and

d. ambifixal position classes: classes whose members include prefixes and suffixes in paradigmatic opposition.

In the "rule-block approach" advocated in that earlier paper, these four position-class phenomena were seen as reflections of four kinds of interactions that might exist among a language's blocks of inflectional rules:

a. Parallel position classes are defined by 'parallel rule blocks' which differ in their applicational sequence but whose application in the realization of particular morphosyntactic property sets defaults to that of a single block of underspecified realization rules. 
b. A portmanteau position class is defined by a 'portmanteau rule block' that introduces one or more portmanteau affixes but whose application in the realization of particular property sets defaults to the successive application of two or more rule blocks.

c. Reversible position classes are defined by 'reversible rule blocks' whose applicational sequence depends on the morphosyntactic property set being realized.

d. An ambifixal position class is defined by an 'ambifixal rule block' in which rules of prefixation and rules of suffixation compete.

The "rule-block approach" portrays parallel, portmanteau, reversible and ambifixal position classes as manifestations of the way in which rule blocks participate in the definition of a language's paradigm function. For this reason, this approach makes the definition of that paradigm function quite complex. Where $\mathrm{A}$ and $\mathrm{B}$ are parallel rule blocks, the evaluation of a paradigm function defined in terms of $\mathrm{A}$ and $\mathrm{B}$ depends on a third rule block to whose application the application of $\mathrm{A}$ and $\mathrm{B}$ both default. Where $\mathrm{A}$ is a portmanteau rule block, the evaluation of a paradigm function defined in terms of $\mathrm{A}$ depends on two or more other rule blocks to whose successive application the application of A defaults. Where A and B are reversible rule blocks, the evaluation of a paradigm function defined in terms of $\mathrm{A}$ and $\mathrm{B}$ depends on the applicational sequence A : B in the realization of some morphosyntactic property sets but on the sequence B : A in the realization of others. Where $\mathrm{A}$ is an ambifixal rule block, the evaluation of a paradigm function defined in terms of $\mathrm{A}$ involves rules of prefixation and rules of suffixation competing for A's applicational sequence.

This "rule-block approach" provides a credible account of the phenomenon of reversible position classes, but the micromorphological approach improves upon that account. To appreciate this, consider the 1993 analysis of Fula affix ordering afforded by the "rule-block approach". This approach portrays the ordering reversal exhibited by forms such as mballumAmi' 'I helped you (sg.)' as a reflection of the way in which the Fula paradigm function is defined in terms of rule blocks. The paradigm function's default clause (15) causes the application of the block of rules realizing subject agreement ('Block SBJ') to precede the application of the block of rules realizing object agreement ('Block OBJ'), as in the realization of forms such as mballumibe' 'I helped them'; but for certain property sets, the paradigm function's default clause is overridden by (16), which causes the application of Block OBJ to precede that of Block SBJ, as in the realization of mballumAmi' 'I helped you (sg.)'. 
(15) $\operatorname{PF}(\langle X, \sigma\rangle)=[$ Block oBJ: [Block SBJ : [Block TNS : $\langle X, \sigma\rangle]]]$

(16) $\mathrm{PF}(\langle X, \tau\rangle)=[$ Block SBJ: [Block oBJ : [Block TNS : $\langle X, \tau\rangle]]]$, where $\tau$ is an extension of $\{\mathrm{SBJ}:\{1 \mathrm{sg}\}$ Ser5 $\}$ and of either $\{\mathrm{OBJ}:\{2 \mathrm{sg}\}\}$ or $\{$ OBJ: $\{3 \mathrm{sg}$ CL. 1$\}\}$.

The micromorphological analysis is simpler in that the ordering of rule blocks specified in the definition of the Fula paradigm function in (11) is not overridden; instead, the ordering reversal is simply a low-level morphotactic consequence of the way in which rule (10b) diverges from the usual pattern of rule conflation in Block II. In this way, the micromorphology hypothesis makes it possible to dispense with the theoretical construct of reversible rule blocks. ${ }^{15}$

\subsubsection{Whether an affixation rule places its affix as a prefix or a suffix apparently depends on whether another rule applies}

In this sort of deviation from the canonical pattern of rule application, a rule introduces an affixal exponent that is seemingly a prefix in some word forms but a suffix in others, and the choice between these two possibilities apparently depends on whether some other particular rule applies as part of a word form's definition. In Swahili, the relative affixes in Table 11 express the noun class (i.e., gender and number) of a verb's relativized argument.

Table 11: Swahili relative affixes (Ashton 1944, 110ff)

\begin{tabular}{lcccccc}
\hline Gender & $1 / 2$ & $3 / 4$ & $5 / 6$ & $7 / 8$ & $9 / 10$ & $11 / 10$ \\
\hline sg & ye & o & lo & cho & yo & o \\
pl & o & yo & yo & vyo & zo & zo \\
\hline
\end{tabular}

In some instances, these affixes appear suffixally, as in (17a); the verb form in (17a) is a "general relative", a form which lacks any overt exponent for tense and which is unspecific in its time reference (Ashton 1944, 111).

15 The micromorphology hypothesis likewise makes it possible to dispense with the notion of portmanteau rule blocks, as I show in $\S 3.3 .1$ below. On the other hand, the notion of ambifixal rule blocks is indispensable, since even under the micromorphology hypothesis, rules of prefixation and suffixation may compete as members of the same rule block; I examine a case of precisely this sort from Swahili immediately below. Parallel rule blocks are likewise indispensable, but see Stump (to appear b, c) for a new conception of them. 
But if the verb is overtly marked by a prefix expressing either tense or negation, then the relative affix seems to be prefixed right after the mark of tense/negation, as in $(17 \mathrm{~b}, \mathrm{c})$. Thus, the rules of relative concord are apparently rules of prefixation in the company of rules of tense/negation, but are otherwise rules of suffixation.
a. vitabu a-vi-soma-vyo
Hamisi
books.CL.8 SBJ:CL.1-OBJ:CL.8-read-REL:CL.8 Hamisi.CL.1
'the books which Hamisi reads'
b. vitabu a-na-vyo-vi-soma Hamisi
books.CL.8 SBJ:CL.1-TNS-REL:CL.8-OBJ:CL.8-read Hamisi.CL.1
'the books which Hamisi is reading'
c. vitabu a-si-vyo-vi-soma Hamisi
books.CL.8 SBJ:CL.1-NEG-REL:CL.8-OBJ:CL.8-read Hamisi.CL.1
'the books which Hamisi does not read'

The micromorphology hypothesis, however, affords a different understanding of these facts, as formulated in (18)-(20). By itself, a relative affix $\alpha$ follows a verb's stem, in accordance with the rules in $(18 \mathrm{~m}-\mathrm{w})$. But these rules of relative affixation may also conflate with rules of tense or negation (e.g., those in $(18 \mathrm{x}, \mathrm{y}))$, in accordance with (20). This difference in ordering between the affix -vyo in (17a) and the same affix in $(17 \mathrm{~b}, \mathrm{c})$ is purely an effect of rule conflation: when a relative suffix $\alpha$ is conflated with a tense/negation prefix $\beta$, the resulting conflated affix $\beta$ - $\alpha$ conforms to the prefixal ordering pattern usual for $\beta$; in $(17 \mathrm{~b}, \mathrm{c})$, for example, the conflated affixes na-vyo and si-vyo exhibit the prefixal ordering of $n a$ - and si-rather than the suffixal ordering exhibited by -vyo on its own. Even so, -vyo is a suffix in all three of the sentences in (17): it is suffixed to the verb stem in (17a), but suffixed to $n a$ - in (17b) and to $s i$ - in (17c).

(18) Simple rules of inflectional affixation for a fragment of Swahili verb morphology

\section{Blocks III, I}

Where $\alpha \in\{$ SBJ, OBJ $\}$, a rule realizing $\{$ SBJ: $\gamma\} \in$ Block III, and a rule realizing $\{$ OBJ: $\gamma\} \in$ Block $\mathbf{I}$,

Rules of subject and object concord
a. $\quad$ SBJ: $\{$ CL. 1$\}\}$ : prefix $a-$
g. $\{\alpha:\{$ CL. 6$\}\}$ : prefix ya-
b. $\{$ OBJ: $\{$ CL. 1$\}\}$ : prefix $m$ -
h. $\{\alpha:\{$ CL. 7$\}\}$ : prefix $k i-$
c. $\{\alpha:\{$ CL. 2$\}\}$ : prefix wa-
i. $\{\alpha:\{$ CL. 8$\}\}$ : prefix vi-
d. $\{\alpha:\{$ CL. 3$\}\}$ : prefix $u-$
j. $\quad\{\alpha:\{$ CL. 9$\}\}$ : prefix $i-$
e. $\{\alpha:\{$ CL. 4$\}\}$ : prefix $i$ -
k. $\{\alpha:\{$ CL. 10$\}\}$ : prefix $z i-$
f. $\{\alpha:\{$ CL. 5$\}\}$ : prefix $l i-$
l. $\{\alpha:\{$ CL. 11$\}\}$ : prefix $u$ - 


\section{Block II}

Simple rules of relative concord

m. $\{$ REL: $\{$ CL. 1$\}\}$ : suffix $-y e$

S. $\{$ REL: $\{$ CL. 7$\}\}$ : suffix - cho

n. $\{$ REL: $\{$ CL. 2$\}\}:$ suffix $-O$

t. $\{$ REL: $\{$ CL. 8$\}\}$ : suffix -vyo

o. $\{$ REL: $\{$ CL. 3$\}\}:$ suffix $-O$

u. $\{$ REL: $\{$ CL. 9$\}\}:$ suffix $-y o$

p. $\{$ REL: $\{$ CL. 4$\}\}$ : suffix $-y o$

v. $\{$ REL: $\{$ CL. 10$\}\}$ : suffix $-z o$

q. $\{$ REL: $\{$ CL. 5$\}\}$ : suffix $-l o$

W. $\{$ REL: $\{$ CL. 11$\}\}$ : suffix $-O$

r. $\{$ REL: $\{$ CL. 6$\}\}$ : suffix $-y o$

Simple rules of tense and negation

x. $\quad\{$ prs $\}$ : prefix $n a-$

y. $\{$ neg $\}$ : prefix si-

etc.

(19) $\mathrm{PF}(\langle X, \sigma\rangle)=[$ Block III : [Block II : [Block I : $\langle X, \sigma\rangle]]]$

(20) Conflated rules

For any rule $\mathrm{A}$ of relative concord and any rule B of tense/negation, [A C B] is a conflated rule.

All of the rules in (18m-y) may be seen as occupying Block II; by Pāṇini's principle, conflated members of Block II (e.g., those in (21)) invariably override the simple rules which they conflate (e.g., those in (22)).

(21) a. $\{$ REL: $\{$ CL. 8$\}$ prs $\}$ : prefix na-vyo- $(=[(18 \mathrm{t})$ C $(18 \mathrm{x})])$

b. $\{$ REL: $\{$ CL. 8$\}$ neg $\}$ : prefix si-vyo- $(=[(18 \mathrm{t})$ C $(18 \mathrm{y})])$

(22) a. $\{$ prs $\}$ : prefix $n a-$

$(=(18 \mathrm{x}))$

b. $\{$ neg $\}$ : prefix si-

$(=(18 \mathrm{y}))$

c. $\{$ REL: $\{$ CL. 8$\}\}$ : suffix - vyo

$(=(18 \mathrm{t}))$

\begin{tabular}{|lccc|}
\hline Simple rules of & $(18 \mathrm{i})$ & $(18 \mathrm{t})$ & $(18 \mathrm{a})$ \\
inflectional affixation & & & \\
Properties realized & OBJ:\{CL.8\} & REL: $\{$ CL.8 $\}$ & SBJ: $\{$ CL. 1$\}$ \\
Rule block & Block I & Block II & Block III \\
Stem: soma & $\rightarrow$ visoma & $\rightarrow$ visomavyo & $\rightarrow$ avisomavyo \\
\hline
\end{tabular}

Figure 7: The realization of Swahili avisomavyo 'which s/he reads' (paradigm cell $\langle$ soma, $\{$ SBJ: $\{$ CL.1\} OBJ:\{CL.8\} REL:\{CL.8\} TNS:none POL:pos $\}\rangle)$

The analysis proposed here has several advantages over the analysis developed by Crysmann and Bonami (2016). 


\begin{tabular}{|c|c|c|c|c|c|}
\hline $\begin{array}{l}\text { Rules of } \\
\text { inflectional } \\
\text { affixation }\end{array}$ & $\begin{array}{l}\text { simple } \\
\text { conflated }\end{array}$ & $(18 \mathrm{i})$ & {$\left[(\underbrace{18 \mathrm{t}),(18 \mathrm{y})})_{\mathrm{C}(18 \mathrm{y})}\right](=(21 \mathrm{~b}))$} & (18a) & [by (20)] \\
\hline Properties r & ealized & OBJ: $\{$ CL. 8$\}$ & REL: $\{$ CL. 8$\}$, POL:neg & SBJ: $\{$ CL. 1$\}$ & \\
\hline Rule block & & Block I & Block II & Block III & \\
\hline Stem: soma & & $\rightarrow$ visoma & $\rightarrow$ sivyovisoma & $\rightarrow$ asivyovisoma & \\
\hline
\end{tabular}

Figure 8: The realization of Swahili asivyovisoma 'which s/he does not read' (paradigm cell $\langle$ soma, \{SBJ:\{CL.1\} OBJ:\{CL.8\} REL:\{CL.8\} TNS:none POL:neg\}))

- In my analysis, a single, ambifixal block of rules is responsible for filling either (a) the suffixal position occupied by a simple affix such as -vyo in a-vi-soma-vyo 'which s/he reads' (Figure 7) or (b) the prefixal position occupied by a simple affix such as $n a$ - in $a$-na-visoma 's/he is reading them' or by a conflated affix such as si-vyo- in a-si-vyo-vi-soma 'which s/he does not read' (Figure 8). By contrast, Crysmann and Bonami's analysis assigns the tense/negation prefixes and the relative concord suffixes to distinct templatic slots, offering no explanation for the mutual exclusion of affixes occupying these slots; indeed, relations of direct competition between rules of prefixation and rules of suffixation require a special stipulation in their theory.

- The fact that a relative concord affix is adjacent to the tense/negation prefix in any form in which both appear is a direct consequence of my analysis but is a coincidence in Crysmann and Bonami's analysis.

- In my analysis, the fact that the relative concord suffixes follow the verb stem in affirmative general relatives is directly related to the fact that affirmative general relatives lack any tense/polarity prefix. In Crysmann and Bonami's analysis, this fact is portrayed as a coincidence: a relative concord's suffixal position is determined by an affirmative general relative's property set without reference to the fact that affirmative general relatives are precisely the relative forms in which neither polarity nor tense receives any affixal expression.

- In my analysis, the relative concords are uniformly suffixal, being suffixed either to a verb's stem or to its tense/polarity prefix; in 
Crysmann and Bonami's analysis, the relative concords are sometimes prefixes and sometimes suffixes. ${ }^{16}$

\subsubsection{The same rule apparently applies in various positions in the sequence of rule applications}

In Pengo (Dravidian; Odisha, India), a verb's subject agreement is sometimes represented more than once in its morphology. The verb HUR 'see', for example, has the past- and perfect-tense paradigms in Table 12. In the past tense, each form has the preterite suffix - $t$ followed by a single agreement suffix, but in the perfect tense, the perfect suffix -na (sandhi form $-n$ ) follows the subject agreement suffix and is, in certain forms, itself followed

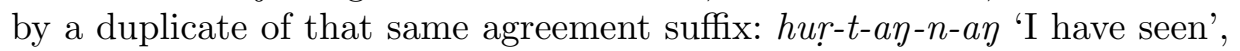

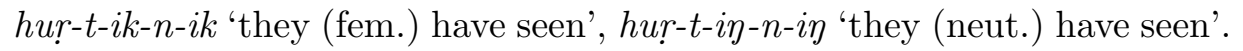

Table 12: Past- and perfect-tense forms of Pengo HuR 'see'

(Burrow \& Bhattacharya 1970, 62-70)

\begin{tabular}{|c|c|c|c|c|}
\hline & Agr & & Singular & Plural \\
\hline \multirow[t]{5}{*}{ Past } & 1 st & & hur-t-ay & EXCL. huṛ-t-ap, INCL. huṛ-t-as \\
\hline & 2nd & & hur-t-ay & hur-t-ader \\
\hline & $3 \mathrm{rd}$ & $\mathrm{m}$. & hur-t-an & hur-t-ar \\
\hline & & f. $\}$ & & huṛ-t-ik \\
\hline & & n. & huṛ-t-at & hur-t-in \\
\hline \multirow[t]{5}{*}{ Perfect } & 1st & & huret-ay-n-ay & EXCL. huṛ-t-ap-na, INCL. hur-t-ah-na \\
\hline & 2nd & & huṛ-t-ay-na & hur-t-ader-na \\
\hline & $3 \mathrm{rd}$ & $\mathrm{m}$. & huṛ-t-an-na & hurr-t-ar-na \\
\hline & & f. $\}$ & & hur-t-ik-n-ik \\
\hline & & n. & hur-t-at-na & hur-t-in-n-in \\
\hline
\end{tabular}

In a theory which fails to countenance rule conflation, such affix doubling is puzzling: the rule block containing the subject-agreement rules (Block II in (23)) must seemingly apply both before and after the block containing the perfect rule (Block III) - not always, but only in the realization of $\{1$ $\mathrm{sg}\},\{3 \mathrm{pl} \mathrm{fem}\}$ and $\{3 \mathrm{pl}$ neut $\}$ subject agreement. A theory incorporating

${ }^{16}$ Crysmann and Bonami's theory of Information-based Morphology is problematic for other reasons, most centrally because it entails the reintroduction of Bloomfieldian morphemes as the atoms of a word form's structural representation; that is, it necessitates the abandonment of the amorphousness hypothesis (footnote 3 ). This is a critical issue, but detailed discussion of it would be out of place here. 
rule conflation, by contrast, need only specify that rules $(23 \mathrm{~b}),(23 \mathrm{j})$ and (23k) conflate with rule (23l), as in (24); the conflated rules that result (listed in (25)) belong to Block III, where they override rule (231) in the definition of certain forms.

(23) Analysis of a fragment of Pengo verb morphology

Block I: Preterite rule

a. $\{$ TNS:preterite $\}$ : suffix $-t$

Block II: Subject-agreement rules

b. $\{1 \mathrm{sg}\}$ : suffix $-a \eta$

c. $\{2 \mathrm{sg}\}$ : suffix $-a y$

d. $\{3 \mathrm{sg}\}$ : suffix $-a t$

e. $\{3$ sg masc $\}$ : suffix $-a n$

f. $\{1 \mathrm{pl} \mathrm{excl}\}$ : suffix $-a p$

g. $\{1 \mathrm{pl}$ incl $\}$ : suffix -as

h. $\{2 \mathrm{pl}\}$ : suffix -ader

i. $\quad\{3 \mathrm{pl} \mathrm{masc}\}$ : suffix $-a r$

j. $\quad\{3 \mathrm{pl}$ fem $\}$ : suffix $-i k$

k. $\quad\{3 \mathrm{pl}$ neut $\}$ : suffix $-i \eta$

Block III: Perfect rule l. $\{$ PERF: +$\}$ : suffix $-n a$

m. Paradigm function: $\operatorname{PF}(\langle X, \sigma\rangle)=[$ Block III : [Block II : [Block I : $\langle X, \sigma\rangle]]]$

(24) Where $\mathrm{A} \in\{(23 \mathrm{~b}),(23 \mathrm{j}),(23 \mathrm{k})\},[\mathrm{A}$ (C) (23l)] is a conflated rule.

(25) a. $\quad\{1$ sg perf $\}$ : suffix $-n(a)-a \eta \quad$ [(23b) C (23l)]

b. $\quad\{3 \mathrm{pl}$ fem perf $\}$ : suffix $-n(a)-i k$ [(23j) C) (23l)]

c. $\{3 \mathrm{pl}$ neut perf $\}$ : suffix $-n(a)-i \eta[(23 \mathrm{k})$ C) (23l)]

In this analysis, the forms hurtayna 'you (sg.) have seen' and hurtaynay 'I have seen' are in fact parallel in their definition: each involves the application of a single rule from each of the three blocks, as in Figures 9 and 10 .

\begin{tabular}{|lccc|}
\hline $\begin{array}{l}\text { Simple rules of } \\
\text { inflectional affixation }\end{array}$ & $(23 \mathrm{a})$ & $(23 \mathrm{c})$ & $(23 \mathrm{l})$ \\
Properties realized & TNS:preterite & SBJ: $\{2 \mathrm{sg}\}$ & PERF: + \\
Rule block & Block I & Block II & Block III \\
Stem: hur & $\rightarrow$ hurt & $\rightarrow$ hurtay & $\rightarrow$ hurtayna \\
\hline
\end{tabular}

Figure 9: The realization of Pengo hurtayna 'you (sg.) have seen' (paradigm cell $\langle h u r,\{\mathrm{SBJ}:\{2 \mathrm{sg}\}$ TNS:preterite PERF: +$\}\rangle$ ) 


\begin{tabular}{|c|c|c|c|c|c|}
\hline $\begin{array}{l}\text { Rules of } \\
\text { inflectional } \\
\text { affixation }\end{array}$ & $\begin{array}{l}\text { simple } \\
\text { conflated }\end{array}$ & (23a) & $(23 b)$ & $\frac{(\underbrace{23 \mathrm{~b}),(23 \mathrm{l}}_{[(23 \mathrm{~b}) \text { C }(23 \mathrm{l})})}{]}$ & [by (24)] \\
\hline \multicolumn{2}{|c|}{ Properties realized } & TNS:preterite & SBJ: $\{1 \mathrm{sg}\}$ & SBJ: $\{1 \mathrm{sg}\}$, PERF: + & \\
\hline \multicolumn{2}{|l|}{ Rule block } & Block I & Block II & Block III & \\
\hline \multicolumn{2}{|l|}{ Stem: hur } & $\rightarrow$ hurt & $\rightarrow$ hurtay & $\rightarrow$ hurtaynay & \\
\hline
\end{tabular}

Figure 10: The realization of Pengo hurtannay 'I have seen' (paradigm cell $\langle$ hur, $\{\mathrm{SBJ}:\{1 \mathrm{sg}\}$ TNS:preterite PERF: +$\}\rangle$ )

\subsubsection{Two rules' order of application apparently depends on their interaction with a third rule}

It sometimes happens that the relative order in which two rules apply is sensitive to whether some third rule applies. An example of this sort in Huave (Embick \& Noyer 2001, 576-577; Ryan 2010, 781-782) involves a rule (26a) realizing reflexive voice through the suffixation of -ay, a rule (26b) realizing first-person agreement through the suffixation of - os (sandhi form -as), and a rule (26c) realizing plural agreement through the suffixation of -on. Apparently, the application of (26a) ordinarily precedes that of (26b), as in (27); but in the definition of words in which (26c) also applies, the application of (26b) apparently precedes that of (26a), as in (28).

(26) Rules for a fragment of Huave inflectional morphology

a. $\{$ refl $\}$ : suffix $-a y$

b. $\{1$ st $\}$ : suffix $-o s$

c. $\{\mathrm{pl}\}$ : suffix - on

(27) a. tekohč-ay-os

PAST.cut-REFL-1

'I cut (past) myself.'

b. *tekohč-as-ay

PAST.cut-1-REFL

(28) a. tekohč-as-ay-on

PAST.cut-1-REFL-PL

'we cut (past) ourselves'

b. *tekohč-ay-as-on

PAST.cut-REFL-1-PL 
As in the Fula case discussed above, this evidence seems to suggest that Huave rule blocks apply in different orders depending on the morphosyntactic property set being realized. The micromorphology hypothesis, however, makes it possible to avoid this conclusion. Instead, one need only assume that the rules in (26) belong to a single block and that they conflate with one another as in (29), whose conflated rules likewise belong to the same, single block. According to this analysis, tekohčayos 'I cut (past) myself' and tekohčasayon 'we cut (past) ourselves' have the respective definitions in Figures 11 and 12.
(29) a. [(26b) C (26a)]
$=\{1$ st refl $\}:$ suffix - ay-os
b. $[(26 \mathrm{c})$ C $(26 \mathrm{a})]$
$=\{$ refl pl $\}:$ suffix - ay-on
c. $[[(26 \mathrm{c})(\mathrm{C}(26 \mathrm{a})] \mathrm{C}(26 \mathrm{~b})]=\{1$ st refl pl $\}$ : suffix -as-ay-on

\begin{tabular}{|c|c|c|}
\hline $\begin{array}{l}\text { Rules of } \\
\text { inflectional } \\
\text { affixation }\end{array}$ & $\begin{array}{l}\text { simple } \\
\text { conflated }\end{array}$ & $\frac{(\underbrace{26 \mathrm{~b}),(26 \mathrm{a}})}{(26 \mathrm{~b}) \text { C }(26 \mathrm{a})}[$ by (29a)] \\
\hline \multicolumn{2}{|c|}{ Properties realized } & $1^{\text {st }}$ refl \\
\hline \multicolumn{2}{|l|}{ Rule block } & Block I \\
\hline \multicolumn{2}{|c|}{ Past stem: tekohč } & $\rightarrow$ tekohčayos \\
\hline
\end{tabular}

Figure 11: The realization of Huave tekohčayos 'I cut (past) myself' (paradigm cell $\langle k o h \check{c},\{1$ st sg refl pst $\}\rangle)$

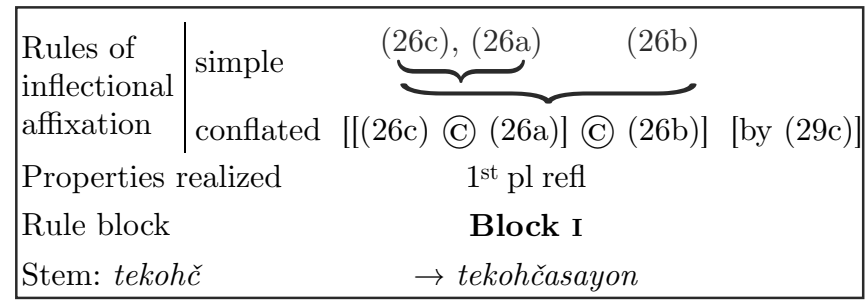

Figure 12: The realization of Huave tekohčasayon 'we cut (past) ourselves' (paradigm cell $\langle k o h \check{c},\{1$ st pl refl pst $\}\rangle$ )

\subsubsection{Sequences of rule applications seem not to be transitive}

Canonically, the sequential application of morphological rules is transitive: if A applies before B and B before C, then A applies before C. But many 
languages exhibit sequential rule applications that fail to exhibit transitivity (Ryan 2010, 780ff). In the Wolof sentences in (30), for example, the sequence of the benefactive, instrumental and causative suffixes does not conform to transitivity; note, in particular, that this deviation from transitivity cannot be attributed to the affixes' semantic scope, since the causative and benefactive suffixes in (30c) do not reflect the relative scope of the operators that they realize.

(30) The nontransitivity of three verbal affixes in Wolof (Buell et al. 2008)

a. Gàllaay togg-al-e-na Faatu yàpp diwtiir.

Gallaay cook-BEN-INST-FIN Faatu meat palm.oil

'Gallaay cooked Faatu some meat with palm oil.'

b. Gàllaay dóór-e-loo-na Faatu xeer.

Gallaay hit-INSTR-CAUS-FIN Faatu stone

'Gallaay made Faatu hit the stone with a stick.'

c. Gàllaay bind-loo-al-na gan g-i xale $y-i$ taalif.

Gallaay write-CAUS-BEN-FIN guest CL-the child CL.PL-the poem

'Gallaay made the children write the visitor a poem.'

The micromorphology hypothesis easily accommodates this sort of nontransitivity, as in (31): the rule B of instrumental morphology conflates with the rule $\mathrm{A}$ of benefactive morphology, the rule $\mathrm{C}$ of causative morphology conflates with rule $\mathrm{B}$, and rule A conflates with rule $\mathrm{C}$. This does not, of course, explain why the three rules conflate in this way. An investigation into the history of Wolof morphology would likely shed light on this pattern of conflation, but from a synchronic point of view, this pattern is, to all appearances, simply morphomic. Once one recognizes rule conflation as a principle of morphotactics, the incidence of such nontransitivity ceases to be problematic.

(31) Some rules of Wolof verb morphology
a. Simple rules
b. Conflated rules
Rule A. $\{$ ben $\}$ : suffix $-a l$
[B (C) A]
Rule B. $\{$ inst $\}$ : suffix $-e$
[C (C) B]
Rule C. $\{$ caus $\}$ : suffix - loo
[A (C) $\mathrm{C}$ ]

\subsection{Anomalies of nonmonotonicity}

The expectation is that a rule of morphology possesses the same intrinsic properties whether it applies alone or in combination with other rules. 
But there are anomalous cases in which this does not hold true. Under the assumptions of the micromorphology hypothesis, the conflation [B (C) A] of rule $\mathrm{B}$ with rule A can become grammaticalized, taking on properties not directly stemming from A and B. In this way, the properties exhibited by a rule applying in isolation may not always be preserved when it is conflated with other rules. In view of this fact, the content attributed to conflated rules in Tables 6 and 7 above should be seen as their default content, subject to modification by processes of grammaticalization. That is, the content expressed by rule [B (C) A] is, in the default case, a monotonic function of the content expressed by rules A and B; but this default is subject to override. There are at least three ways in which the resulting nonmonotonicity may be manifested.

\subsubsection{A rule's domain apparently depends on whether a particular rule applies subsequently}

In the default case, rule [B (C) A] applies to exactly the same stems as rule A; once it is grammaticalized, however, [B (C) A] may come to have a domain distinct from that of $\mathrm{A}$. On one hand, [B (C) A] may apply where A does not; on the other hand, A may apply where [B (C) A] does not. Consider, for example, English derivative adjectives in -ical. As the examples in (32) show, derivatives in -ical sometimes have counterparts in -ic, but not all do; at the same time, some derivatives in -ic lack counterparts in -ical. These examples show that -ical has been grammaticalized as a suffix whose domain does not exactly match that of -ic. This otherwise puzzling state of affairs is not unexpected under the assumptions of the micromorphology hypothesis.

$\begin{array}{lll}X & X \text { ic } & X \text { ical } \\ \text { history } & \text { historic } & \text { historical } \\ \text { cycle } & \text { cyclic } & \text { cyclical } \\ \text { whimsy } & { }^{\text {whimsic }} & \text { whimsical } \\ \text { nonsense } & *_{\text {nonsensic }} & \text { nonsensical } \\ \text { ion } & \text { ionic } & \text { *ionical } \\ \text { base } & \text { basic } & \text { *basical }\end{array}$

\subsubsection{A rule's productivity apparently depends on whether a particular rule applies subsequently}

By the measure of potential productivity (= category-conditioned degree of productivity; Baayen 1993; 2009), -abil-ity is more productive than either 
-able or -ity is by itself. ${ }^{17}$ Thus, in the newspaper texts in the Corpus of Contemporary American English (COCA; Davies 2008), the simple suffixes -ity and -able have .002 and .008 as their respective degrees of productivity, while the conflated suffix -abil-ity has an overall productivity of .012; that is, nouns of the type Xability exhibit a higher proportion of innovations than either adjectives of the type Xable or nouns of the type Xity. (This is not a pattern that can be generalized to all combinations of affixes; for example, the combination -ic-ity is much lower in productivity (.004) than the simple suffix -ic (.007).) This evidence embodies the fact, widely noted but never satisfactorily explained, that an affix $x$ whose productivity is generally restricted may exhibit much higher productivity in the presence of a particular affix $y$; citing examples of this sort noted by Aronoff (1976), Williams (1981) refers to this phenomenon as the potentiation of $x$ by $y$.

The micromorphology hypothesis affords a simple explanation for this phenomenon. The hypothesis entails that if a conflated rule [B (C) A] becomes grammaticalized, it may coexist with its component rules $\mathrm{A}$ and $\mathrm{B}$ as a distinct rule; in that case, it should be perfectly possible for it to diverge in productivity from both $\mathrm{A}$ and $\mathrm{B}$. Thus, under the micromorphology hypothesis, '-able potentiates -ity' simply means that the -ability rule (33a) resulting from the conflation of the -ity rule (33b) with the -able rule (33c) is more productive than (33b) itself. (See Bochner 1992, 65ff for a cogent discussion of this point with somewhat different terminology.)

(33) a. $\quad$ suffix - ability $|\mathrm{V} \rightarrow \mathrm{N}|$ ' $\mathrm{Z}$ ' $\rightarrow$ 'state of being able to be Zed'

b. suffix -ity $|\mathrm{A} \rightarrow \mathrm{N}|$ ' $\mathrm{Z}$ ' $\rightarrow$ 'state of being Z'

c. $\quad$ suffix - able $|\mathrm{V} \rightarrow \mathrm{A}|$ ' $\mathrm{Z}$ ' $\rightarrow$ 'able to be Zed'

\subsubsection{Two rules apparently realize less content separately than they do together}

In the finite inflection of an Old English verb, neither the morphomic suffix $-e$ nor the default plural suffix $-n$ expresses the subjunctive mood by itself; but the conflated suffix - $e-n$ unambiguously expresses the subjunctive plural. The inflection of SCIERAN 'cut, shear' in Table 13 illustrates. As this example shows, simple affixes exhibiting the phenomenon of underdetermination (a failure to realize a word form's full morphosyntactic content; Stump 2001, 7-9) may, when conflated, fully determine a word form's content. The kind of underdetermination exhibited by the Old English subjunctive plural is sometimes described as significative absence - the as-

${ }^{17}$ In a given corpus, the potential productivity of morphology $m$ is the ratio of hapaxes with morphology $m$ to the number of tokens with $m$. 
sociation of one or more morphosyntactic properties with an absence of morphology as the effect of a kind of process of elimination: if a word form lacks the morphology for property $p$, it must express the contrasting property $q$ (even though there is no overt morphology realizing $q$ ).

Table 13: Finite conjugation of Old English SCIERAN 'cut, shear'

\begin{tabular}{lllll}
\hline & & & Present & Past \\
\hline Indicative & Singular & 1st & scier-e & scear \\
& & $\begin{array}{l}\text { 2nd } \\
\text { 3rd }\end{array}$ & scier-e-st & scēar-e \\
& & scier-e-p & scear \\
& Pcier-ap & scēar-o-n \\
\hline Subjunctive & Singular & scier-e & scēar-e \\
& Plural & scier-e-n & scēar-e-n \\
\hline Imperative & Singular & scier & \\
& Plural & scier-ap & \\
\hline
\end{tabular}

Under the micromorphology hypothesis, significative absence may have the effect of conferring more specific content on a conflated affix whose component affixes do not entail that content; as a consequence, the conflated affix may be grammaticalized as an expression of that more specific content. In Old English, for example, it is plausible to assume that the -en rule (34a) resulting from the conflation of the $-n$ rule $(34 \mathrm{~b})$ with the $-e$ rule $(34 \mathrm{c})$ has been grammaticalized as a pure and simple mark of the subjunctive plural, contrasting with all of a verb's other fully conflated suffixes.

(34) a. $\{$ pl $\}$ : suffix $-e-n$, grammaticalized as $\{$ sbjv $\mathrm{pl}\}$ : suffix $-e n$

b. $\{\mathrm{pl}\}: \operatorname{suffix}-n$

c. \{\} : suffix $-e$

In this way, the micromorphology hypothesis constitutes a kind of bridge between what Blevins (2006) calls "constructive" descriptions and "abstractive" descriptions of a language's inflectional morphology: a constructive description identifies the content of each of a word form's exponents and the manner of their combination; an abstractive description is concerned not with individual exponents, but with the manner in which the full conflation of a word form's inflectional exponents distinguishes it from word forms realizing other paradigm cells. In other words, an abstractive descrip- 
tion of an inflectional system is deducible from a constructive description $\mathrm{C}$ of that system through the maximal conflation of C's rules of inflection.

\subsection{Parallelisms between single rules and sequences of rules}

A prediction of the micromorphology hypothesis is that the application of sequences of morphological rules will in some cases parallel that of single rules. In the domain of inflection, for example, conflated rules and simple rules may coexist as members of the same rule block, so that their application is alike in important ways. This prediction is certainly borne out.

\subsubsection{A simple rule seems to stand in paradigmatic opposition to a sequence of rules}

If a language's morphology may include both simple affixes and conflated affixes, the natural expectation is that a simple affix and a conflated affix should be able to stand in paradigmatic opposition. This expectation is widely fulfilled by the incidence of portmanteau affixes. In Latin, for example, the default formation of a synthetic passive verb form is one exhibiting the morphology of the corresponding active form plus a suffixal formative - $(u) r$; this suffix is ordinarily word-final (e.g., audi-unt-ur 'they are heard'), though in second-person singular forms, it is positioned before rather than after the subject-agreement suffix (e.g. audī-r-is 'you (sg) are heard'). This pattern - corresponding active morphology plus - $(u) r$, in some order - holds for all person/number combinations but one: whereas -tis is the usual subject-agreement marker for the second person plural active, the expression of the corresponding passive involves neither -tis nor $-(u) r$, but instead involves a special portmanteau suffix -min̄ realizing both second-person plural subject agreement and passive voice (e.g., audi$\min \bar{\imath}$ 'you (pl.) are heard'). Under the assumptions of the micromorphology hypothesis, the simple -min $\bar{r}$ rule (35a) and the conflated -untur rule (35b) coexist as members of the same rule block; for this reason, the morphology of forms such as audī-min̄ 'you (pl.) are heard' and audi-unt-ur 'they are heard' is defined in parallel fashion, as in Figure 13. 
Table 14: Present indicative forms of Latin AUDīRE 'hear'

\begin{tabular}{|c|c|c|c|}
\hline & & Active & Passive \\
\hline \multirow[t]{3}{*}{ Singular } & 1 & audi-ō & audi-o-r \\
\hline & 2 & audī-s & audī-r-is \\
\hline & 3 & audi-t & audī-t-ur \\
\hline \multirow[t]{3}{*}{ Plural } & 1 & audī-mus & audī-mu-r \\
\hline & 2 & audi-tis & audī-minī \\
\hline & 3 & audi-unt & audi-unt-ur \\
\hline
\end{tabular}

(35) Rules of inflectional suffixation for a fragment of Latin verb morphology

a. $\quad\{2 \mathrm{pl}$ pass $\}$ : suffix $-\min \bar{\imath}$

b. $[(35 \mathrm{~d})(\mathrm{C})(35 \mathrm{c})] \quad[=\{3 \mathrm{pl}$ pass $\}$ : suffix -unt-ur $]$

c. $\{3 \mathrm{pl}\}$ : suffix -unt

d. $\{$ pass $\}$ : suffix - ur

\begin{tabular}{|c|c|c|c|}
\hline $\begin{array}{l}\text { Rules of } \\
\text { inflectional } \\
\text { affixation }\end{array}$ & $\begin{array}{l}\text { simple } \\
\text { conflated }\end{array}$ & $\begin{array}{l}(35 \mathrm{a}) \\
-\end{array}$ & $\frac{(\underbrace{35 d),(35 d)})(35 c)]}{(35 c)}$ \\
\hline $\begin{array}{l}\text { Properties } \\
\text { Rule block }\end{array}$ & & 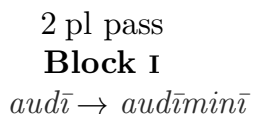 & $\begin{array}{l}3 \text { pl pass } \\
\text { Block I } \\
\text { aud } \rightarrow \text { audiuntur }\end{array}$ \\
\hline
\end{tabular}

Figure 13: The realization of Latin audīmini 'you are heard' (paradigm cell $\langle a u d \bar{\imath}$, $\{2 \mathrm{pl}$ prs ind pass $\}\rangle$ ) and audiuntur 'they are heard'(paradigm cell $\langle a u d \bar{\imath},\{3 \mathrm{pl}$ prs ind pass $\}\rangle)$

This approach to the analysis of portmanteau affixes is very different from the approach proposed by Stump (1993). In that earlier approach (alluded to in $\S 3.1 .1$ above), I assumed that the position occupied by a portmanteau affix subsumes two or more adjacent affix positions - e.g., that the Latin portmanteau suffix - min $\bar{\imath}$ simultaneously occupies both the affix position of -unt and that of -ur. On that assumption, a portmanteau affix is introduced by a special portmanteau rule block whose application defaults to the successive application of two or more other rule blocks; for instance, the application of the rule block $\mathrm{P}$ to which the $-\min \bar{\imath}$ rule belongs defaults 
to the successive application of the blocks $\mathrm{Q}$ and $\mathrm{R}$ to which the - unt rule and the -ur rule respectively belong, as in (36).

(36) By default, [Block $\mathbf{P}:\langle X, \sigma\rangle]=[$ Block $\mathbf{R}:[$ Block $\mathbf{Q}:\langle X, \sigma\rangle]]$

This earlier approach accounts for portmanteau affixes at a rather abstract level, attributing them to rule blocks distinct from those that introduce the successive affixes to which they stand in opposition. The micromorphological approach proposed here is simpler in that it assigns a portmanteau affixation rule (e.g., the - min $\bar{\imath}$ rule) to the very same block as the conflated rules to which it is opposed (e.g., the - untur rule). Thus, no default relationship among rule blocks comparable to (36) is required in this approach; that is, this approach allows the theoretical construct of portmanteau rule blocks to be dispensed with. Instead, portmanteau affixes simply reflect the coexistence of simple and conflated rules of affixation within the same rule block.

See Stump (to appear a) for extensive discussion of two cases from Swahili in which simple and conflated members of the same rule block enter into competition.

\subsubsection{An affix is subject to a morphotactic restriction that seems sensitive to a nonadjacent affix}

Logically, the relations of adjacency in which a conflated affix $\alpha-\beta$ participates are distinct from those in which its component affixes $\alpha$ and $\beta$ participate; for instance, in the context $\mathrm{X} \alpha-\beta \mathrm{Y}, \alpha-\beta$ is adjacent to both $\mathrm{X}$ and $Y$, but $\alpha$ is not adjacent to $Y$, nor is $\beta$ adjacent to $X$. As a consequence of this difference, there may be morphotactic restrictions that $\alpha$ - $\beta$ satisfies that neither $\alpha$ nor $\beta$ satisfies. Sanskrit imperatives provide a striking example of this sort of restriction. In the second-person singular imperative active, Sanskrit verbs behave differently according to their conjugation-class membership; these differences are summarized in Table 15 (overleaf). ${ }^{18}$

As the table shows, verbs belonging to the thematic conjugations (classes 1, 4, 6 and 10) simply use their bare stem as their second-person singular imperative active form (e.g., viśa 'enter!'). In the athematic conjugations (classes 2, 3, 5, 7, 8 and 9), the situation is more complex. In

${ }^{18}$ A verbal lexeme's present-system stem is used in the present and imperfect indicative, the present optative, and the imperative. Athematic verbs have present-system stems with alternating strong and weak forms; since the weak form of an athematic verb's present-system stem is what is used in the second-person singular imperative active, that is the stem form listed here. 
Table 15: Second-person singular imperative active forms in Sanskrit

\begin{tabular}{|c|c|c|c|c|c|}
\hline \multirow{2}{*}{$\begin{array}{l}\text { Present- } \\
\text { system } \\
\text { conjugation }\end{array}$} & \multirow{2}{*}{$\begin{array}{l}\text { Member } \\
\text { lexeme and } \\
\text { present-system stem }\end{array}$} & \multicolumn{4}{|c|}{ Inflectional realization } \\
\hline & & $\begin{array}{l}\mathrm{C}_{-} \\
-\mathrm{dhi}\end{array}$ & $\begin{array}{l}\mathrm{V}_{-} \\
-\mathrm{hi}\end{array}$ & - & $\begin{array}{c}\text { Portmanteau } \\
\text {-āna }\end{array}$ \\
\hline \multicolumn{6}{|l|}{ Thematic } \\
\hline 1st (a) & BHŪ 'be' : bhava- & & & bhava & \\
\hline 4th (ya) & NAH 'bind' : nahya- & & & nahya & \\
\hline 6th (á) & VIŚ 'enter' : viśa- & & & viśa & \\
\hline 10th (aya) & CINT 'think' : cintaya- & & & cintaya & \\
\hline \multicolumn{6}{|l|}{ Athematic } \\
\hline \multirow[t]{2}{*}{ 2nd (root) } & I 'go' : i- & & i-hi & & \\
\hline & DVIṢ 'hate' : dviṣ- & dviḍ-ḍhi & & & \\
\hline 3rd (reduplicating) & BHṚ 'carry' : bibhṛ- & & bibhṛ-hi & & \\
\hline \multirow[t]{2}{*}{5 th $($ no) } & ĀP 'obtain' : āpnu- & & āpnu-hi & & \\
\hline & SU 'press out' : sunu- & & & sunu & \\
\hline 7th (nasal infixing) & YUJ ‘join' : yuñj- & yung-dhi & & & \\
\hline 8th (o) & KR 'do' : kuru- & & & kuru & \\
\hline \multirow[t]{2}{*}{$9 \operatorname{th}(\mathrm{n} \overline{\mathrm{a}})$} & KRĪ ‘buy' : krīṇ̄- & & krīṇ̄-hi & & \\
\hline & AŚ 'eat' : aśn̄̄- & & & & aś-āna \\
\hline
\end{tabular}

the simplest cases, the suffix is -(d)hi: - $d h i$ (or a sandhi variant) after a stem-final consonant (yung-dhi 'join!') and - $h i$ after a stem-final vowel ( $i$-hi 'go!'). In the 5th conjugation, one would expect to find - $h i$, since the sign of the 5 th conjugation is (in the second singular imperative active) a stem-final $-n u$. But the $-h i$ suffix only appears if the root $\mathrm{X}$ to which $-n u$ attaches is itself consonant-final. If $\mathrm{X}$ ends in a vowel, then - $h i$ is omitted: $\bar{a} p$-nu-hi 'obtain!' (with the consonant-final root $\bar{a} p$-), but su-nu 'press out!' (with the vowel-final root $s u$ ). This is an unexpected pattern, given that - $h i$ would not be adjacent to the root in either case but would in both cases have the same immediate phonological environment (a preceding - $\mathrm{nu}$ ). Under the micromorphology hypothesis, however, this pattern can be seen as involving a conflated suffix - nu- $h i$ that requires the immediately preceding segment to be a consonant.

The 9 th conjugation presents an additional twist. Here, too, one would expect to find $-h i$, since the sign of the 9 th conjugation is (in the second singular imperative active) a stem-final $-n \bar{\imath}$. But in this conjugation, $-h i$ only appears if the root $\mathrm{X}$ to which $-n \bar{\imath}$ attaches is vowel-final: $k r \bar{\imath}-n \bar{\imath}-h i$ 'buy!'. If $\mathrm{X}$ ends in a consonant, then both $-n \bar{\imath}$ and $-h i$ are supplanted by a portmanteau suffix - $\bar{a} n a$ : aś-̄ana 'eat!'. This seemingly messy situation 
is clarified under the micromorphology hypothesis: in the 9th conjugation, the suffix of the second-person singular imperative active is the conflated affix $-n \bar{\imath}$ - $h i$ after a root-final vowel and the portmanteau - $\bar{a} n a$ after a rootfinal consonant. Without the micromorphology hypothesis, appnuhi would have to be seen as involving nonadjacent phonological conditioning, and the complementarity of the simple affix - $\bar{a} n a$ with the affix sequence $-n \bar{\imath}-h i$ in 9th-conjugation imperatives such as aśāna and krīñ̄hi would require a special stipulation.

The micromorphology hypothesis therefore affords the analysis in (37).

(37) Where L is a verbal lexeme that

- belongs to an athematic conjugation,

- has R as its root,

- has X as its present-system stem, and

- L has $w$ as its second-person singular imperative active form,

then the form of $w$ is as in Table 16 .

Table 16: Second-person singular imperative active forms of lexemes belonging to athematic present-system conjugations

\begin{tabular}{lcccc}
\hline & $\begin{array}{c}\text { Where } \mathrm{L} \\
\text { belongs to }\end{array}$ & \multicolumn{2}{c}{ w arises through the application } & \multirow{2}{*}{ provided that } \\
\cline { 3 - 4 } a. & \multirow{2}{*}{ Conj5 } & {$[(38 \mathrm{c})(\mathrm{C})(38 \mathrm{a})]$} & $\mathrm{R}$ & $\mathrm{R}$ ends in a consonant \\
& $(38 \mathrm{a})$ & $\mathrm{R}$ & $\mathrm{R}$ ends in a vowel \\
\hline b. & \multirow{2}{*}{ Conj9 } & {$[(38 \mathrm{c})(\mathrm{C})(38 \mathrm{~b})]$} & $\mathrm{R}$ & $\mathrm{R}$ ends in a vowel \\
& $(38 \mathrm{~d})$ & $\mathrm{R}$ & $\mathrm{R}$ ends in a consonant \\
\hline c. & other athematic & $(38 \mathrm{c})$ & $\mathrm{X}$ & \\
\hline
\end{tabular}

(38) Simple rules of inflectional affixation

a. $\{$ Conj5 athematic $\}$ : suffix $-n u$

b. $\{$ Conj9 athematic $\}$ : suffix $-n \bar{\imath}$

c. $\{$ athematic 2 sg impv act $\}$ : suffix $-h i$

d. $\{$ Conj9 athematic 2 sg impv act $\}$ : suffix $-\bar{a} n a$

In this analysis, the second-person singular imperative active form of a verb belonging to the 5 th or 9 th conjugation is, in every case, subject to a phonological condition by which the choice of affix is sensitive to the root-final segment to which it is adjacent. 


\subsubsection{Two affixes are partially alike in form and content}

It is common for affixes to exhibit vestiges of morphological complexity. Consider, for instance, the primary and secondary agreement suffixes in Sanskrit. The primary suffixes are used to express subject agreement in the indicative of the present and future tenses; the secondary suffixes are used in other contexts, such as the imperfect and the optative. As the partial (active-voice) inventory in Table 17 shows, a primary suffix often resembles the corresponding secondary suffix, but with some additional segment at the end: for instance, primary $-m i$, $-s i$ and $-t i$ correspond to secondary $-m,-s$ and $-t$.

Table 17: Primary and secondary agreement suffixes in Sanskrit (active voice suffixes)

\begin{tabular}{|c|c|c|c|c|}
\hline & & Singular & Dual & Plural \\
\hline \multirow{3}{*}{$\begin{array}{l}\text { Primary } \\
\text { endings }\end{array}$} & $1 \mathrm{st}$ & $-m i$ & -vas & -mas \\
\hline & 2nd & $-\mathrm{si}$ & -thas & -tha \\
\hline & $3 \mathrm{rd}$ & $-\mathrm{ti}$ & $-\operatorname{tas}$ & -anti \\
\hline \multirow{3}{*}{$\begin{array}{l}\text { Secondary } \\
\text { endings }\end{array}$} & $1 \mathrm{st}$ & $-\mathrm{m}$ & -va & $-m a$ \\
\hline & 2nd & $-s$ & -tam & - ta \\
\hline & $3 r d$ & $-\mathrm{t}$ & -tām & -an \\
\hline
\end{tabular}

A reasonable hypothesis is that the $i$ appearing in $-m i,-s i$, - $t i$, and -anti was at one time a temporo-modal verbal enclitic. With time, $i$ was reanalyzed as a verb ending that entered into conflation with various secondary agreement suffixes. As the status of $-i$ as a simple affix decayed, conflated suffixes such as $-m-i$ were ultimately reanalyzed as simple affixes, nevertheless preserving their similarity to the secondary suffix that had served as their first component. This historical trajectory, schematized in (39), entails that a conflated rule of affixation may outlive one of its parts but continue to coexist with the other part.

(39) The history of Sanskrit - $m i$

a. Pre-Sanskrit I:

(i) $\{1 \mathrm{sg}\}:$ suffix $-m$

(ii) $\{$ ind nonpast $\}$ : encliticize $\# i$

b. Pre-Sanskrit II:

(i) $\{1 \mathrm{sg}\}:$ suffix $-m$

(ii) $\{$ ind nonpast $\}:$ suffix $-i$ 
c. Pre-Sanskrit III:

(i) $\{1 \mathrm{sg}\}$ : suffix $-m$

(ii) $\{$ ind nonpast $\}$ : suffix $-i$

(iii) [(ii) (C) (i)], i.e., $\{1 \mathrm{sg}$ ind nonpast $\}$ : suffix $-m i$

d. Sanskrit:

(i) $\{1 \mathrm{sg}\}$ : suffix $-m$

(ii) $\{1 \mathrm{sg}$ ind nonpast $\}$ : suffix $-m i$

\section{Discussion}

Most current theories of grammar liken affixed forms to artichokes, with bract-like affixes layered individually onto a heart-like stem. The micromorphology hypothesis invites a different comparison, according to which affixed forms are like bladderferns, whose multiply pinnate leaves themselves have smaller leaves, just as conflated affixes consist of smaller affixes. The evidence discussed here decisively favors the latter metaphor, suggesting that an adequate theory of morphotactics requires a richer algebra than is generally assumed in current morphology.

One possibility raised by the micromorphology hypothesis is that there are rules of inflectional affixation whose only manifestation is as components of conflated rules; this is in effect the proposal of Harris (2017) that languages may exhibit dependent affixes whose appearance is contingent on that of a carrier affix. A potential example of this sort comes from Chhatthare Limbu (Kiranti; Nepal). In Chhatthare Limbu, the affix -n expresses negation and often appears more than once in a negative verb form's inflectional morphology. The negative nonpast paradigm of the verb LoMMA 'beat' in Table 18 illustrates; in this table, the negative affix $-n$ is in boldface. The appearance of this affix seems always to be dependent on that of an immediately preceding carrier affix; in some cases this affix is a prefix, in others a suffix, and not every affix is available to serve as a carrier. Further investigation of Chhatthare Limbu verb inflection is necessary, but a plausible hypothesis is that the rule

$$
\{\text { neg\} : suffix }-n
$$

serves only as a basis for creating conflated rules. (See Stump to appear c for discussion of another example of this type, also from Limbu.)

Another phenomenon whose incidence is compatible with (if not predicted by) the micromorphology hypothesis is that of Wackernagel affixes (Nevis \& Joseph 1993) - affixes that appear as the second morph in a word form, e.g., in the positions marked ' $\mathrm{X}$ ' in the schemata in (40). 
Table 18: Negative nonpast paradigm of the Chhatthare Limbu verb LoMMA 'beat' (third-person object forms; Tumbahang 2007, 220)

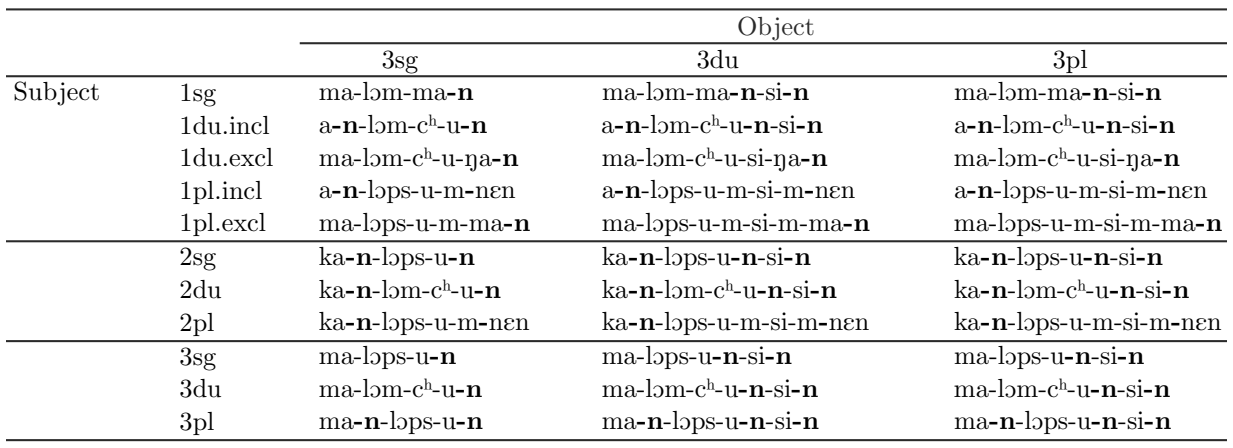

(40) a. $\operatorname{prefix}_{1} \mathrm{X}$ stem

b. prefix $_{2} \mathrm{X}$ prefix $_{1}$ stem

c. stem $\mathrm{X}$

A hypothesis that deserves scrutiny is that this kind of pattern arises because

- Wackernagel affixes are suffixes;

- rules of Wackernagel suffixation conflate with simple prefixation rules;

- rules of suffixation conflate with rules of Wackernagel suffixation; and

- rules of Wackernagel suffixation and the conflated rules to which they give rise occupy an inflectional system's outermost block of rules.

The micromorphology hypothesis raises a host of questions for future research. Are there constraints on rule conflation? If there are rules that inherently require conflation (such as the negative rule of $-n$ suffixation in Chhatthare Limbu), are there also rules that inherently resist conflation? How does rule conflation interact with phonology? Is the allomorphy of a conflated affix deducible from the allomorphy of its component affixes?

A question of particular interest is whether all complex affixes are conflated affixes. The complex affixes discussed here have all been continuous strings arising as an effect of rule conflation; but can complex affixes arise in other ways? Should circumfixes be seen as complex affixes whose parts are discontinuous? If so, then they arise not as an effect of rule conflation 
(as I have defined it here; §1.2), but as an effect of the composition of a rule of prefixation with a rule of suffixation (where rule composition is essentially equated with the mathematical notion of function composition). Bauer (1988) postulates a class of complex morphological markings which he labels synaffixes: synaffixes include continuous conflated affixes such as -ic-al (§3.2.1) and -abil-ity (§3.2.2) but also discontinuous affixes such as circumfixes as well as complex markings some or all of whose components are nonconcatenative. Perhaps the principle of rule conflation developed here should be subsumed by a wider theory of synaffixes in which rule composition and rule conflation both have a role.

For instance, should a circumfix be seen as a complex affix whose two parts are discontinuous? If so, then conflated affixes are only one kind of complex affix, circumfixes should be seen as complex affixes that result from the composition (rather than the conflation) of a rule of prefixation and a rule of suffixation. In addition, the examples of rule conflation discussed here have all involved rules of affixation, but as it is defined, conflation could, logically, involve nonconcatenative rules as well.

The micromorphology hypothesis is only one of the ways in which current conceptions of the algebra of morphotactics should likely be enriched. Other enrichments seem motivated as well. For example, certain kinds of evidence suggest that exponence relations are of at least two kinds. In the pair of Swahili sentences in (41), the prefix vi- serves three related functions. In all three functions, it expresses noun class 8 . In the noun vi-tabu, it identifies 'books' as a member of class 8; in the verb form vi-me-anguka, it marks noun-class agreement with a class 8 subject; and in the verb form $u$-me-vi-ona, it marks noun-class agreement with a class 8 object. It is therefore clear that $v i$ - is an intrinsic exponent of class 8 and that it expresses additional content according to its position - as a noun prefix, as a verb prefix in the position reserved for subject-agreement markers, and as a verb prefix in the position reserved for object-agreement markers. This distinction between intrinsic and positional exponence (schematized in (42)) is not a peculiarity of vi-, but permeates the Swahili inflectional system.

(41) a. Vi-tabu vi-me-anguka.

CL8-book SBJ:CL8-COMPL-fall.down

'The books have fallen down.'

b. U-me-vi-ona vi-tabu?

SBJ:2SG-COMPL-OBJ:CL8-see CL8-book

'Have you seen the books?' 

(42) vi- intrinsic exponence: $\{$ CL. 8$\}$
positional exponence: as a noun prefix: noun class membership
as a verb prefix: subject agreement
object agreement

Consider likewise the Swahili verb forms in (43). In (43a-c), the prefix $s i$ - is an intrinsic exponent of negation but expresses additional content according to its position. In (43a), it additionally expresses first-person singular subject agreement; in this function, it precludes the appearance of both the default negative prefix $h a-(\mathrm{cf} .(43 \mathrm{~d}))$ and the first-person singular subject-agreement prefix ni- (cf. (43e)), but it does not preclude the appearance of the tense prefix. In (43b), si- serves as the usual expression of negation for relative verb forms, and in (43c), as the usual expression of negation for the subjunctive mood; in both of these uses, it precludes the appearance of any tense prefix, but does not express subject agreement and does not preclude the appearance of subject-agreement morphology. Thus, si- participates in the relations of intrinsic and positional exponence summarized in (44).

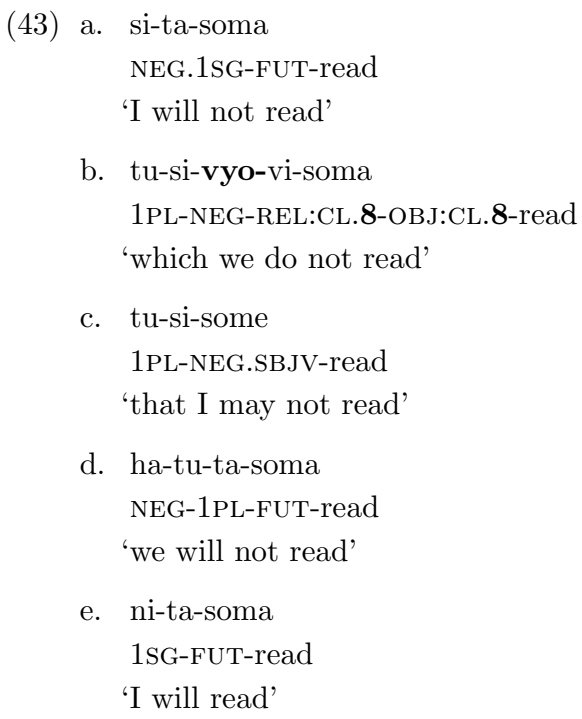


From this evidence, it seems clear that morphotactics cannot simply be equated with morpheme concatenation; a richer, more carefully articulated theory of morphotactics is required.

\section{References}

Anderson, Stephen R. 1977. On the formal description of inflection. Proceedings of the Chicago Linguistic Society 13. 15-44.

Anderson, Stephen R. 1986. Disjunctive ordering in inflectional morphology. Natural Language and Linguistic Theory 4. 1-31.

Anderson, Stephen R. 1992. A-Morphous morphology. Cambridge: Cambridge University Press.

Arnott, David Whitehorn. 1970. The nominal and verbal systems of Fula. Oxford: Oxford University Press.

Aronoff, Mark. 1976. Word-formation in generative grammar (Linguistic Inquiry Monographs 1). Cambridge, MA: MIT Press.

Aronoff, Mark. 1994. Morphology by itself. Stems and inflectional classes. Cambridge, MA: MIT Press.

Ashton, Ethel O. 1944. Swahili grammar. Essex: Longman.

Baayen, R. Harald. 1993. On frequency, transparency and productivity. In Booij \& van Marle (1993, 181-208).

Baayen, R. Harald. 2009. Corpus linguistics in morphology: Morphological productivity. In A. Luedeling and M. Kyto (eds.) Corpus linguistics. An international handbook. Berlin \& New York: Mouton de Gruyter. 900-919.

Bauer, Laurie. 1988. A descriptive gap in morphology. In G. Booij and J. van Marle (eds.) Yearbook of morphology 1988. Dordrecht: Foris. 17-27.

Blevins, James P. 2006. Word-based morphology. Journal of Linguistics 42. 531-573.

Bochner, Harry. 1992. Simplicity in generative morphology. Berlin \& New York: Mouton de Gruyter.

Bonami, Olivier and Gregory Stump. 2017. Paradigm function morphology. In A. Hippisley and G. Stump (eds.) The Cambridge handbook of morphology. Cambridge: Cambridge University Press. 449-481.

Booij, Geert and Jaap van Marle (eds.). 1993. Yearbook of morphology 1992. Dordrecht: Kluwer.

Buell, Leston, Mariame Sy and Harold Torrence. 2008. The syntax of mirror principle violations in Wolof. Handout from the 2008 International Morphology Meeting, Vienna, February 2008.

Burrow, Thomas and Sudhibhushan Bhattacharya. 1970. The Pengo language. Oxford: Oxford University Press.

Crysmann, Berthold and Olivier Bonami. 2016. Variable morphotactics in informationbased morphology. Journal of Linguistics 52. 311-374.

Davies, Mark. 2008. The corpus of contemporary American English: 450 million words, 1990 present. Available online at http://corpus.byu.edu/coca/. 
Embick, David and Rolf Noyer. 2001. Movement operations after syntax. Linguistic Inquiry 32. 555-95.

Gazdar, Gerald, Ewan H. Klein, Geoffrey K. Pullum and Ivan A. Sag. 1985. Generalized phrase structure grammar. Oxford: Blackwell.

Harris, Alice C. 2017. Multiple exponence. Oxford: Oxford University Press.

Janda, Richard D. 1983. "Morphemes" aren't something that grows on trees: Morphology as more the phonology than the syntax of words. In J. F. Richardson, M. Marks and A. Chukerman (eds.) Papers from the Parasession on the Interplay of Phonology, Morphology, and Syntax. Chicago: Chicago Linguistic Society. 79-95.

Luís, Ana and Andrew Spencer. 2005. A paradigm function account of 'mesoclisis' in European Portuguese. In G. Booij and J. van Marle (eds.) Yearbook of morphology 2004. Dordrecht: Kluwer. 177-228.

Nevis, Joel A. and Brian D. Joseph. 1993. Wackernagel affixes: Evidence from Balto-Slavic. In Booij \& van Marle (1993, 93-111).

Ryan, Kevin M. 2010. Variable affix order: Grammar and learning. Language 86. 758-791.

Soukka, Maria. 2000. A descriptive grammar of Noon: A Cangin language of Senegal. Munich: LINCOM Europa.

Spencer, Andrew and Gregory Stump. 2013. Hungarian pronominal case and the dichotomy of content and form in inflectional morphology. Natural Language and Linguistic Theory 31. 1207-1248.

Stewart, Tom and Gregory Stump. 2007. Paradigm Function Morphology and the morphology/syntax interface. In G. Ramchand and C. Reiss (eds.) The Oxford handbook of linguistic interfaces. Oxford: Oxford University Press. 383-421.

Stump, Gregory. 1991. A paradigm based theory of morphosemantic mismatches. Language 67. $675-725$.

Stump, Gregory. 1993. Position classes and morphological theory. In Booij \& van Marle (1993, 129-180).

Stump, Gregory. 2001. Inflectional morphology A theory of paradigm structure. Cambridge: Cambridge University Press.

Stump, Gregory. 2012. The formal and functional architecture of inflectional morphology. In A. R. amd Geert Booij, S. Scalise and A. Karasimos (eds.) Morphology and the architecture of grammar: On-line proceedings of the Eighth Mediterranean Morphology Meeting (MMM8), Cagliari, Italy, 14-17 September 2011. 254-270.

Stump, Gregory. 2016. Inflectional paradigms: Content and form at the syntax-morphology interface. Cambridge: Cambridge University Press.

Stump, Gregory. to appear a. An apparently noncanonical pattern of morphotactic competition. In W. Dressler, F. Gardani, F. Rainer and H. C. Luschützky (eds.) Competition in morphology. Berlin: Springer.

Stump, Gregory. to appear b. Polyfunctionality and the variety of inflectional exponence relations. In F. Kiefer, J. P. Blevins and H. Bartos (eds.) Morphological paradigms and functions. Leiden: Brill.

Stump, Gregory. to appear c. Rules and blocks.

Tumbahang, Govinda Bahadur. 2007. A descriptive grammar of Chhatthare Limbu. Doctoral dissertation. Tribhuvan University.

Williams, Edwin. 1981. On the notions "lexically related" and "head of a word". Linguistic Inquiry 12. $245-274$. 